\title{
The impact of
}

\section{Survivin, WRAP53ß, and Hypoxia}

\section{on treatment response in \\ Head and Neck Cancer}

\author{
Katharina Tiefenböck-Hansson
}

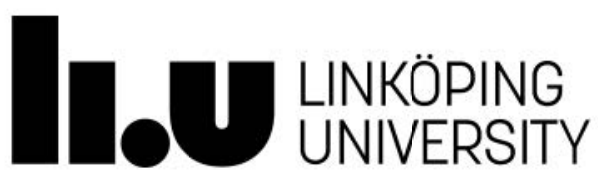

Linköping, 2017

Department of Otorhinolaryngology,

Department of Clinical and Experimental Medicine

Faculty of Health Sciences,

Linköping University,

SE-581 83 Linköping, Sweden 
(C) Katharina Tiefenböck-Hansson, 2017

\author{
Cover Pictures: \\ Images of "The Face" and the Yonaguni Monument taken by Katharina Tiefenböck-Hansson \\ Image of a Red Rock Crab on the Galapagos Islands taken by Fredrik Hansson
}

Published articles have been reprinted with the permission of the copyright holders.

Printed by LiU-Tryck, Linköping 2017

ISBN: 978-91-7685-470-9

ISSN: 0345-0082 
To my beloved FREDRIK, and my beloved family

"If we knew what it was we were doing, it would not be called research, would it?"

- Albert Einstein 


\section{SUPERVISORS}

Karin Roberg, Adjunct Professor

Division of Cell Biology, Department of Clinical and Experimental Medicine, Linköping University, Linköping, Sweden

Department of Otorhinolaryngology in Linköping, Anaesthetics, Operations and Specialty Surgery Center, Region Östergötland

\section{CO-SUPERVISORS}

\section{Lovisa Farnebo, MD PhD}

Division of Speech language pathology, Audiology and Otorhinolaryngology, Department of Clinical and Experimental Medicine, Linköping University, Linköping, Sweden Department of Otorhinolaryngology in Linköping, Anaesthetics, Operations and Specialty Surgery Center, Region Östergötland

Stina Garvin, MD Associate Professor

Divison of Neurobiology, Department of Clinical and Experimental Medicine, Linköping University, Linköping, Sweden

Department of Clinical Pathology, Center for Diagnostics, Region Östergötland

Karin Öllinger, Professor

Division of Cell Biology, Department of Clinical and Experimental Medicine, Linköping University, Linköping, Sweden

\section{OPPONENT}

Eva Brun, MD Associate Professor

Department of Oncology and Radiation Physics, Skåne University Hospital, Lund University, Lund, Sweden

\section{EXAMINATION BOARD}

Stefan Thor, Professor

Department of Clinical and Experimental Medicine, Linköping University, Linköping Sweden

Malin Lindqvist Appell, Associate Professor

Division of Drug Research, Department of Medical and Health Sciences,

Linköping University, Linköping, Sweden

Torbjörn Ramqvist, Associate Professor

Department of Oncology-Pathology, Karolinska Institutet, Stockholm, Sweden 


\section{ABSTRACT}

Squamous cell carcinoma (SCC) is the most common histological type of cancer in the head and neck region and arises in the epithelial mucosa of the upper aerodigestive tract. Approximately one and a half million people are living with the diagnosis. Despite efforts in prevention and advances in treatment, the 5-year survival rate still lies around $60 \%$, and recurrences and second primary tumors remain a problem. Moreover, treatment responses vary from patient to patient, highlighting the need for individually tailored treatments. To make this possible, biomarkers predicting treatment outcome are needed to better guide treatment decisions.

The aim of this thesis was to evaluate the expression of certain proteins and the frequency of certain SNPs (Single nucleotide polymorphisms) in tumor biopsies and cell cultures of head and neck squamous cell carcinomas (HNSCC), and to explore their potential as biomarkers for treatment outcome. Furthermore, we aimed to study the impact of hypoxia on treatment response, epithelial-to-mesenchymal transition (EMT), and induction of cancer stem cells (CSC).

In papers I and II, we investigated two proteins, survivin and WRAP53 $\beta$, using immunohistochemistry (IHC) in tumor biopsies from 40 patients categorized as Nonresponders or Responders to radiotherapy. High expression of survivin and nuclear expression of WRAP53 $\beta$ were significantly more prevalent in the Responder group. The combination of these two factors correlated strongest to overall survival, but not to a significantly higher extent compared to survivin alone. Moreover, when examined separately, a high percentage of p53stained cells and the presence of the SNP FGFR4 Gln388Arg correlated to improved overall survival, whereas the SNP XPD Lys751Gln was associated with worse overall survival. The latter three showed no significant correlations to radiotherapy response. In paper III, the two 


\begin{abstract}
most promising proteins identified in papers I and II were analyzed in a study cohort of 149 tumor biopsies of glottic laryngeal SCC, categorized as T2N0-T3N0. In this patient group, no significant associations between survivin expression and survival could be found. However, expression of cytoplasmic WRAP53 $\beta$ was significantly linked to worse disease-free-survival (DSF) compared to nuclear WRAP53 $\beta$ or negative staining for WRAP53 $\beta$. Positive expression of $\mathrm{p} 16^{\mathrm{INK} 4 \mathrm{a}}$ was found in $7 \%$ of the tumors. The prevalence of $\mathrm{p} 16^{\mathrm{INK} 4 \mathrm{a}}$ was higher in younger patients $(<60)$ and associated with absence of recurrence and longer DSF.
\end{abstract}

In paper IV, five HNSCC cell lines were cultured in normoxic $\left(20 \% \mathrm{O}_{2}\right)$ and hypoxic $\left(1 \% \mathrm{O}_{2}\right)$ conditions and changes in treatment response, EMT profile, and expression of CSC markers were examined. As expected, hypoxia induced EMT and to a certain extent expression of CSC markers. Silencing of the hypoxia-inducible-factor-1 $\alpha$ (HIF-1 $\alpha)$ only partly reversed these effects, suggesting that other mechanisms are involved. Whereas most cell lines became more resistant to treatment in hypoxia, one cell line (LK0412) became more sensitive to cetuximabtreatment in hypoxia, an effect that was revoked by depletion of HIF-1 $\alpha$, suggesting a possible sensitizing effect of HIF-1 $\alpha$ to cetuximab-treatment.

Taken together, WRAP53 $\beta$ appears to be a promising biomarker candidate for treatment outcome in HNSCC, but further evaluation especially on the subcellular localization of WRAP53 $\beta$ is required. Even though the role of survivin in radiotherapy response in glottic SCC seems to be insignificant, it might have a more important role in other HNSCC subsites. As far as the effects of hypoxia, it appears that hypoxia might have a sensitizing effect on cetuximabtreatment in certain cases, which seems to be HIF 1- $\alpha$-dependent. Further studies are required to clarify the importance of this observation. 


\section{POPULAR SCIENCE SUMMARY}

The term Head and Neck Cancer summarizes cancer that arises anywhere in the head and neck region, most commonly on the lips, in the mouth, and in the throat. Long-time use of harming agents like tobacco and alcohol are the main risk factors and lead to changes in the cells, eventually (after many years) resulting in uncontrolled cell growth, cancer. Infection with human papilloma virus (HPV) is another important cause and has become more common, probably because of changes in sexual behavior. Depending on where the cancer is located, patients may have difficulties speaking, swallowing, or breathing. Furthermore the cancer itself can be mutilating, causing a great deal of suffering. The treatment options, which include surgery, radiation, and chemotherapy, are also hard for the patients and cause various side-effects. Unfortunately, not all patients will be helped by these treatments and some patients even get worse. Possible explanations to this variation in treatment response are variations in genes (mutations) and protein expression within the tumor. Increasing our knowledge about factors within the tumor which may predict treatment response, is vital in order to achieve optimal, individualized treatment plans for each patient. Exploring such factors as potential biomarkers for treatment outcome was one of the main aims of this thesis. We found that the proteins survivin and WRAP53 $\beta$ might be promising biomarkers for radiotherapy, but more studies are required to really understand the relation of these factors to treatment effect. Another aim of this thesis was to examine the effects of low oxygen levels (hypoxia) on treatment response. Hypoxia can exist in areas of the tumor, and it is known that treatments are generally less effective in hypoxic tumors. In our study, we found that hypoxia may not be a negative factor in all tumors and might even promote tumor sensitivity to certain treatments. However, this conclusion is based on very modest findings and no general assumptions can be made. Further studies are needed to explore predictive biomarkers and to better understand the complex role of tumor hypoxia for treatment response. 


\section{LIST OF PUBLICATIONS}

This thesis is based on the following papers, which will be referred to in the text by their roman numbers I - IV:

I. Lovisa Farnebo, Katharina Tiefenböck, Anna Ansell, Lena K. Thunell, Stina Garvin and Karin Roberg

Strong expression of survivin is associated with positive response to radiotherapy and improved overall survival in head and neck squamous cell carcinoma patients

Int. J. Cancer: 133, 1994-2003 (2013).

II. Stina Garvin, Katharina Tiefenböck, Lovisa Farnebo, Lena K. Thunell, Marianne Farnebo and Karin Roberg

Nuclear expression of WRAP53 $\beta$ is associated with a positive response to radiotherapy and improved overall survival in patients with head and neck squamous cell carcinoma

Oral Oncology 51 (2015) $24-30$.

III. Katharina Tiefenböck-Hansson, Aaro Haapaniemi, Lovisa Farnebo, Björn Palmgren, Jussi Tarkkanen, Marianne Farnebo, Eva Munck-Wikland, Antti Mäkitie, Stina Garvin and Karin Roberg WRAP53 $\beta$, survivin and $16^{I N K 4 a}$ expression as potential predictors of radiotherapy/ chemoradiotherapy response in T2N0-T3NO glottic laryngeal cancer Oncol Rep. 2017 Oct;38(4):2062-2068.

IV. Emilia Wiechec, Katharina Tiefenböck-Hansson, Lisa Alexandersson, Jan-Ingvar Jönsson and Karin Roberg Hypoxia Mediates Differential Response to Anti-EGFR Therapy in HNSCC Cells Int J Mol Sci. 2017 May; 18(5): 943. 


\section{ABBREVIATIONS}

AF Accelerated fractionation

ARTSCAN Accelerated radio therapy of squamous cell carcinoma in the head and neck

CAIX Carbonic anhydrase IX

CPC Chromosomal passenger complex

Crm1 Chromosome region maintenance 1

CSC Cancer stem cells

CT Chemotherapy

DFS Disease-free survival

DIABLO Direct inhibitor of apoptosis-binding protein with low $\mathrm{pI}$

DNA Deoxyribonucleic acid

DSS Disease-specific survival

EBV Eppstein-Barr-virus

EGFR Epidermal growth factor receptor

EMT Epithelial to mesenchymal transition

ENT Ear, nose, and throat

ERK 1/2 Extracellular signal-regulated kinases 1/2

FBS Fetal bovine serum

FDA Food and Drug Administration

FGFR4 Fibroblast growth factor receptor 4

FN1 Fibronectin 1

GAPDH Glyceraldehyde-3-phosphate dehydrogenase

Gy Gray

HER2 Human epidermal growth factor receptor 2

HIF Hypoxia-inducible factor

HNSCC Head and neck squamous cell carcinoma

HPV Human Papilloma Virus

HPV- HPV negative

HPV+ HPV positive

HRE Hypoxia response elements

HRP Horseradish peroxidase

IAP Inhibition of apoptosis

ICmabS Intrinsic cetuximab sensitivity

ICS Intrinsic cisplatin sensitivity

IHC Immunohistochemistry

IMRT Intensity-modulated radiotherapy

INCENP Inner centromere protein

IR Intrinsic radiosensitivity

IRS Immunnoreactive score

JAK Janus kinase

ISCC Laryngeal squamous cell carcinoma

MAPK Mitogen-activated protein kinase

MDM2 Murine double minute 2

MET Mesenchymal to epithelial transition

mRNA Messenger RNA

NES Nuclear export signal

NR Non-Responders

$\mathrm{O}_{2} \quad$ Oxygen

OD Optical density 


\section{ABBREVIATIONS}

$\begin{array}{ll}\text { OPSCC } & \text { Oropharyngeal squamous cell carcinoma } \\ \text { OS } & \text { Overall survival } \\ \text { OSCC } & \text { Oral squamous cell carcinoma } \\ \text { PCR } & \text { Polymerase chain reaction } \\ \text { pEGFR } & \text { Phosphorylated EGFR } \\ \text { PI3K } & \text { Phosphatidylinositol } 3 \text { kinase } \\ \text { PKC } & \text { Protein kinase C } \\ \text { PLC } \gamma & \text { Phospholipase C } \gamma \\ \text { pO } & \text { Partial pressure of oxygen } \\ \text { pRb } & \text { Retinoblastoma protein } \\ \text { R } & \text { Responders } \\ \text { RFLP } & \text { Restriction fragment length polymorphism } \\ \text { RFS } & \text { Relapse-free survival } \\ \text { RISC } & \text { RNA-induced silencing complex } \\ \text { RNA } & \text { Ribonucleic acid } \\ \text { ROS } & \text { Reactive oxygen species } \\ \text { RPN } & \text { Ribonucleoprotein } \\ \text { RT } & \text { Radiotherapy } \\ \text { RT-qPCR } & \text { Reverse transcriptase - quantitative polymerase chain reaction } \\ \text { scaRNA } & \text { small cajal body specific RNA } \\ \text { SCC } & \text { Squamous cell carcinoma } \\ \text { SDS } & \text { Sodium dodecyl sulphate } \\ \text { Ser20 } & \text { Serine 20 } \\ \text { siRNA } & \text { small interference RNA } \\ \text { SMA } & \text { Spinal muscular atrophy } \\ \text { SMAC } & \text { Secondary mitochondria- derived activator of caspase } \\ \text { SMN } & \text { Survival of motor neuron } \\ \text { SNP } & \text { Single nucleotide polymorphism } \\ \text { snRNP } & \text { small nuclear ribonucleoprotein } \\ \text { STAT3 } & \text { Signal transducer and activator of transcription 3 } \\ \text { TCAB1 } & \text { Telomerase cajal body protein 1 } \\ \text { TERC } & \text { Telomerase RNA component } \\ \text { TERT } & \text { Telomerase reverse transcriptase } \\ \text { Thr34 } & \text { Threonine } 34 \\ \text { TNM } & \text { Tumor-node-metastasis } \\ \text { VEGF } & \text { Vascular endothelial growth factor } \\ \text { WDR79 } & \text { WD repeat domain 79 } \\ \text { WHO } & \text { World Health Organization } \\ \text { WRAP53 } & \text { WD40 encoding RNA antisense to p53 } \\ \text { XIAP } & \text { X-linked inhibitor of apoptosis protein } \\ \text { XPC } & \text { Xeroderma pigementosum complementation group C } \\ \text { XPD } & \text { Xeroderma pigementosum complementation group D } \\ \text { XRCC } & \text { X-ray repair cross-complementing } \\ & \end{array}$




\section{TABLE OF CONTENTS}

POPULAR SCIENCE SUMMARY

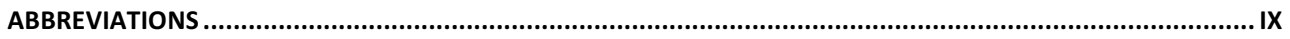

TABLE OF CONTENTS

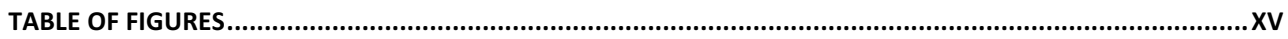

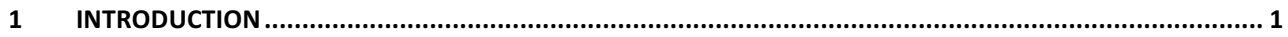

1.1 Head And Neck Squamous CelL CARCinoma (HNSCC) .............................................................

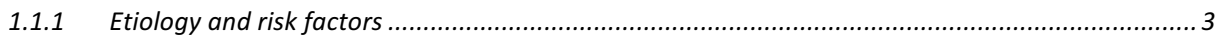

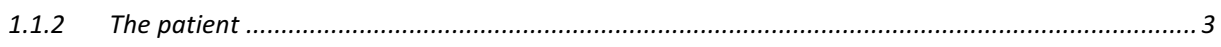

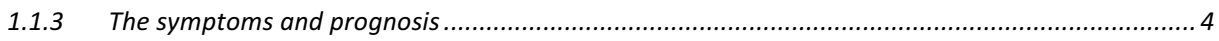

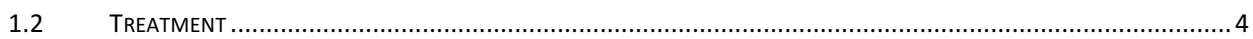

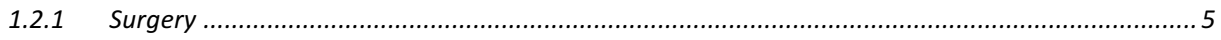

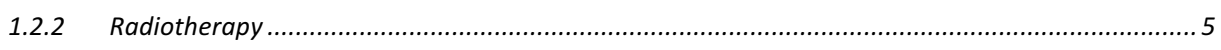

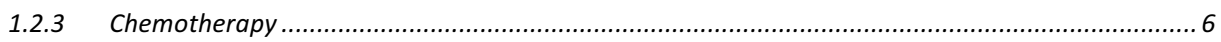

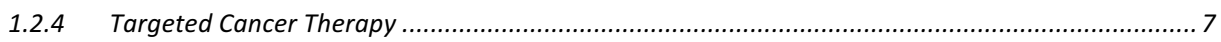

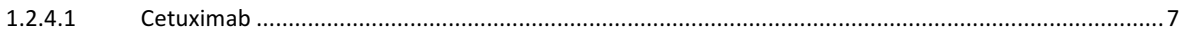

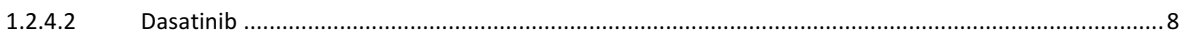

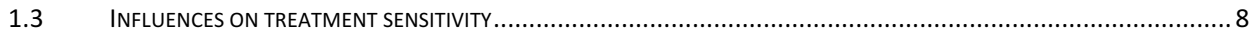

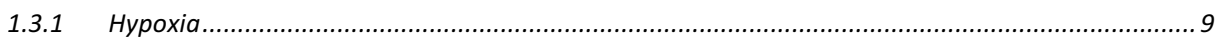

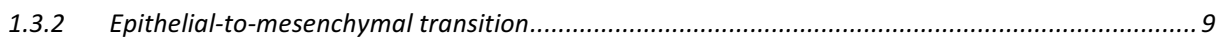

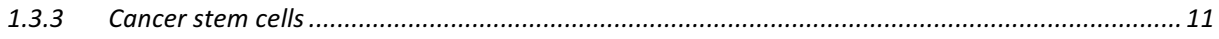

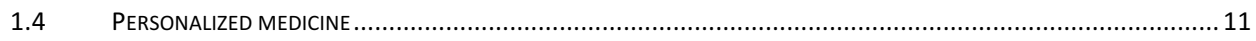

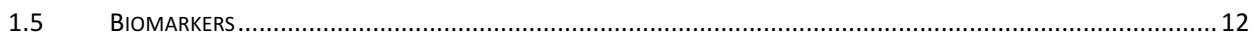




\section{TABLE OF CONTENTS}

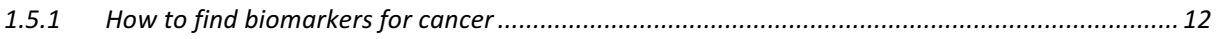

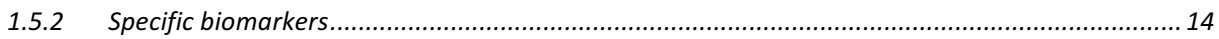

\begin{tabular}{|c|c|}
\hline 1.5.2.1 & Survivin \\
\hline 1.5.2.2 & WRAP53 \\
\hline 1.5.2.3 & HPV and $p 16^{\text {INK4a }}$ \\
\hline 1.5.2.4 & EGFR \\
\hline 1.5.2.5 & HIF-1 $\alpha$ \\
\hline 1.5.2.6 & (1) \\
\hline 1.5.2.7 & orphisms \\
\hline
\end{tabular}

2 AIMS OF THE THESIS...

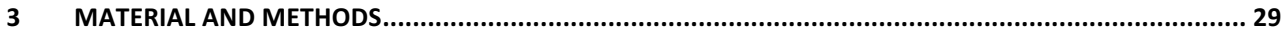

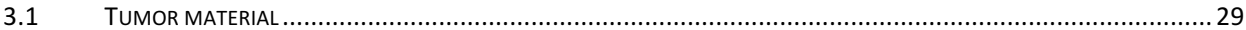

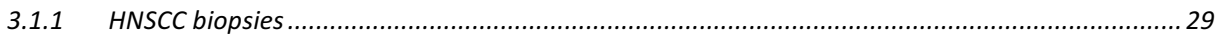

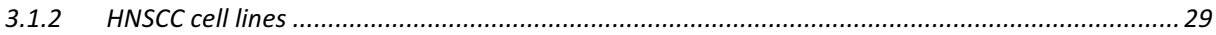

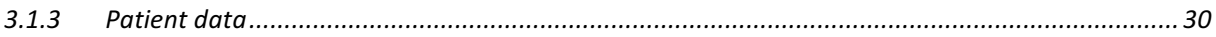

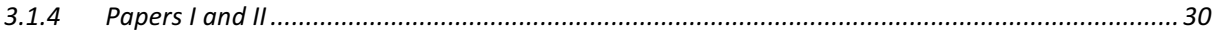

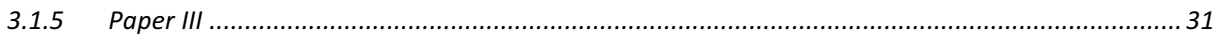

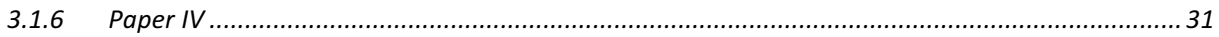

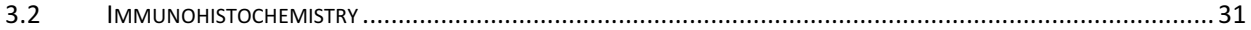

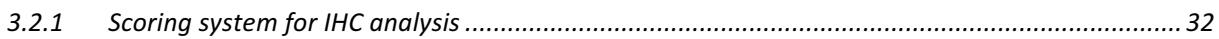

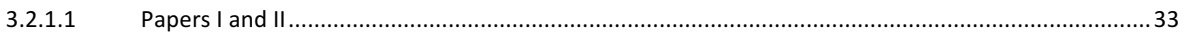

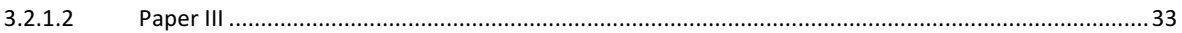

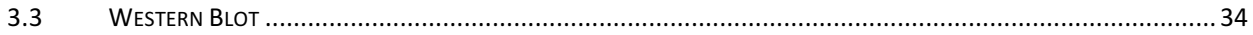

3.4 GENOTYPING BY PCR-RESTRICTION FRAGMENT LENGTH POLYMORPHISM (RFLP) ............................................ 34

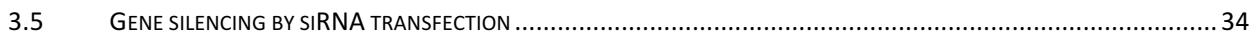

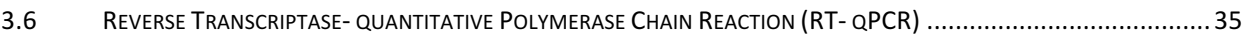

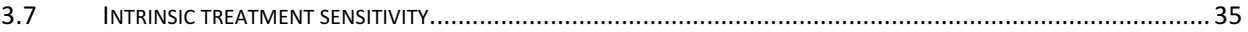

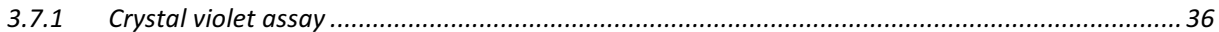

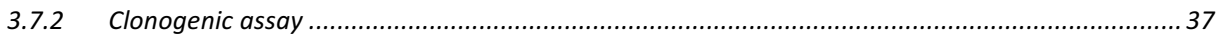




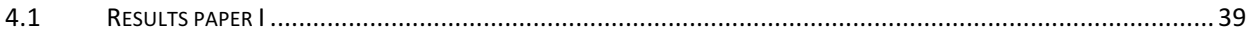

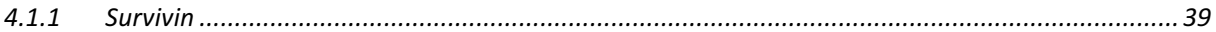

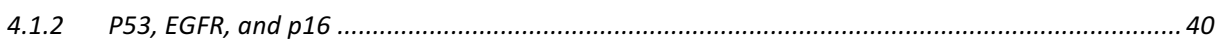

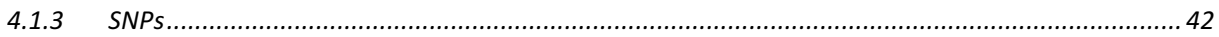

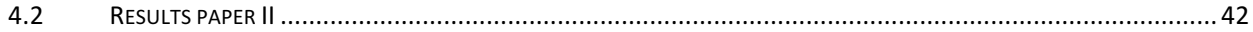

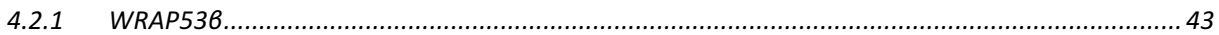

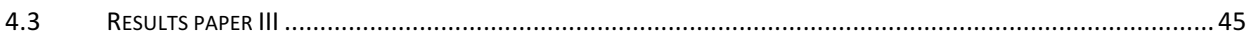

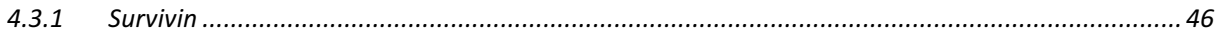

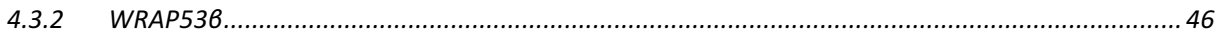

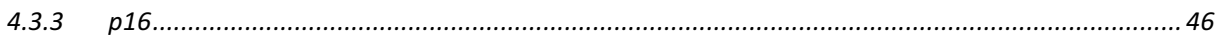

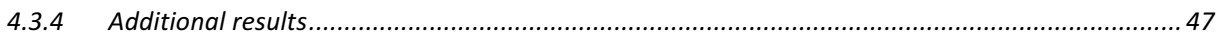

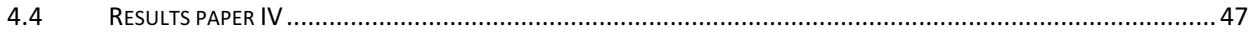

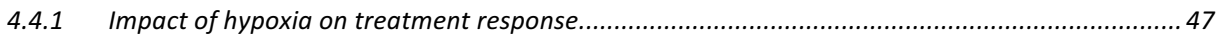

4.4.2 The impact of hypoxia on EMT profile and cancer stem cell markers ........................................48

4.4.3 The impact of HIF-1 $\alpha$ on treatment response, EMT profile, and CSC markers .......................... 49

4.4.4 The impact of hypoxia on EGFR signaling molecules and cetuximab treatment .......................5 50

5.1 THE IMPACT OF SURVIVIN ON TREATMENT RESPONSE AND SURVIVAL IN HNSCC IN GENERAL AND IN GLOTTIC LSCC IN PARTICULAR (PAPERS I AND III)

5.2 THE IMPACT OF WRAP53B ON TREATMENT RESPONSE AND SURVIVAL IN HNSCC IN GENERAL AND IN GLOTTIC LSCC IN PARTICULAR (PAPERS II AND III)

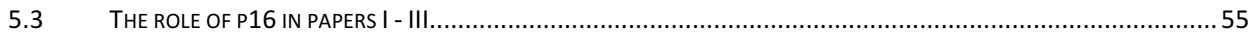

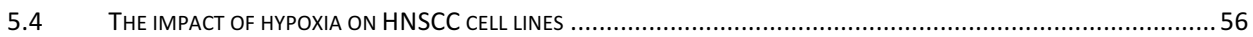

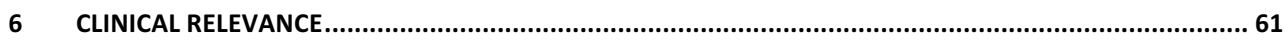

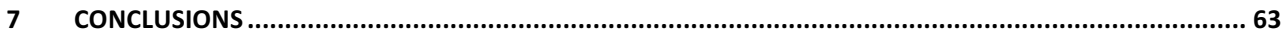


TABLE OF CONTENTS

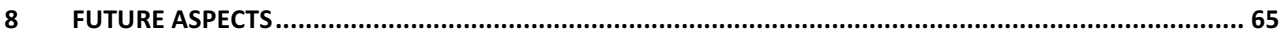

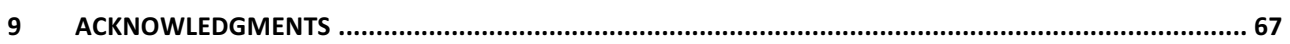

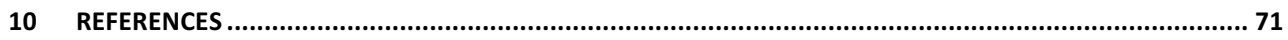




\section{TABLE OF FIGURES}

FIGURE 1. REGIONS OF ORIGIN OF HNSCC. THE HIGHLIGHTED REGIONS ARE THE MOST COMMON AND REPRESENT THE LOCALIZATION OF TUMORS STUDIED IN THIS THESIS.

Figure 2. Modified from “Hallmarks of CANCeR” (60). CAtegories as denoted by Hanahan and Weinberg: Blue: ACQUIRED HALLMARKS OF CANCER; YELLOW: EMERGING HALLMARKS; PURPLE: IMPORTANCE OF THE TUMOR MICROENVIRONMENT, GREEN: ENABLING FACTORS.

FiguRE 3. PROCESSES AND FACTORS INVESTIGATED IN THIS THESIS IN RELATION TO THE HALLMARKS OF CANCER. 14

FigURE 4.. THE FUNCTIONS OF SURVIVIN SHOWN IN RELATION TO ITS SUBCELLULAR LOCALIZATION, A) IN THE CYTOPLASM, B) IN THE NUCLEUS. ADAPTED FROM (62) AND MODIFIED.

FIGURE 5. A) THE TRANSCRIPTION OF WRAP53 GENE IN AN ANTISENSE FASHION TO P53 AND THE GENE PRODUCTS OF WRAP53. B)

THE FUNCTIONS OF WRAP53A AND B (78). C) THE ROLE OF WRAP53B IN CAJAL BODIES. 18

FIGURE 6. THE RELATIONSHIP BETWEEN HIGH-RISK HPV-INFECTION AND P16 OVEREXPRESSION..........................................2

FIGURE 7. SURVIVIN EXPRESSION ACCORDING TO STAINING INTENSITY IN NON-RESPONDERS AND RESPONDERS. 39

FIGURE 8. THE EXPRESSION OF P53 ACCORDING TO STAINING INTENSITY (A) AND POSITIVELY STAINED CELLS (B) IN NON-RESPONDERS AND RESPONDERS.

FIGURE 9. EGFR EXPRESSION ACCORDING TO EGFR SCORE IN NON-RESPONDERS AND RESPONDERS.

FigURE 10. THE EXPRESSION OF WRAP53B ACCORDING TO STAINING INTENSITY (A), POSITIVELY STAINED CELLS (B), AND SUBCELLULAR LOCALIZATION (C) IN NON-RESPONDERS AND RESPONDERS.

FIGURE 11. THE FREQUENCY OF GENOTYPES FOR SNPS RS2287498 AND RS2287499 IN NON-RESPONDERS AND RESPONDERS. ... 45

FiguRE 12. MORPHOLOGICAL CHANGES IN EMT-PROFILE UNDER HYPOXIC CONDITIONS. . .48 



\section{INTRODUCTION}

Cancer is a leading cause of morbidity and mortality worldwide (1) and the majority of the population has come or will come in contact with it, either as patients, relatives, friends or professionals. Cancer causes a lot of personal suffering and is an enormous economic burden to society, a burden that is expected to increase due to both the growth and aging of the population. The term cancer originated from the greek word karkinos and was minted by Hippokrates to describe big superficial tumors $(2,3)$. Other terms are malignant tumors or malignant neoplasms. Siddharta Mukherjee called it „The Emperor of all maladies“, as it is an old disease that has effected and concerned patients, physicians, and researchers for hundreds to thousands of years. In his book he describes the history of this disease and the dedication of physicians and researchers who have made it a goal in their lives to find the 'ultimate cure for cancer' (3). Through time, there have been many theories as to what the causes of cancer are. For instance, it was believed that cancer was the expression of an imbalance in the body fluids or caused and spread by a parasite (2). Nowadays cancer is described as "a group of diseases involving abnormal cell growth with a potential to invade or spread to other parts"(4). Due to huge advances in research on the molecular level in the 20th century we have been able to gain valuable insights into some of the underlying mechanisms of cancer. Still, even though some cancer types can now be cured, we do not fully understand cancer yet, and despite extensive research, no ultimate cancer cure has been found.

\subsection{Head and Neck Squamous Cell Carcinoma (HNSCC)}

This thesis focuses on squamous cell carcinoma arising in the head and neck region (Figure 1, provided and printed with the permission of Lovisa Farnebo (5)). 


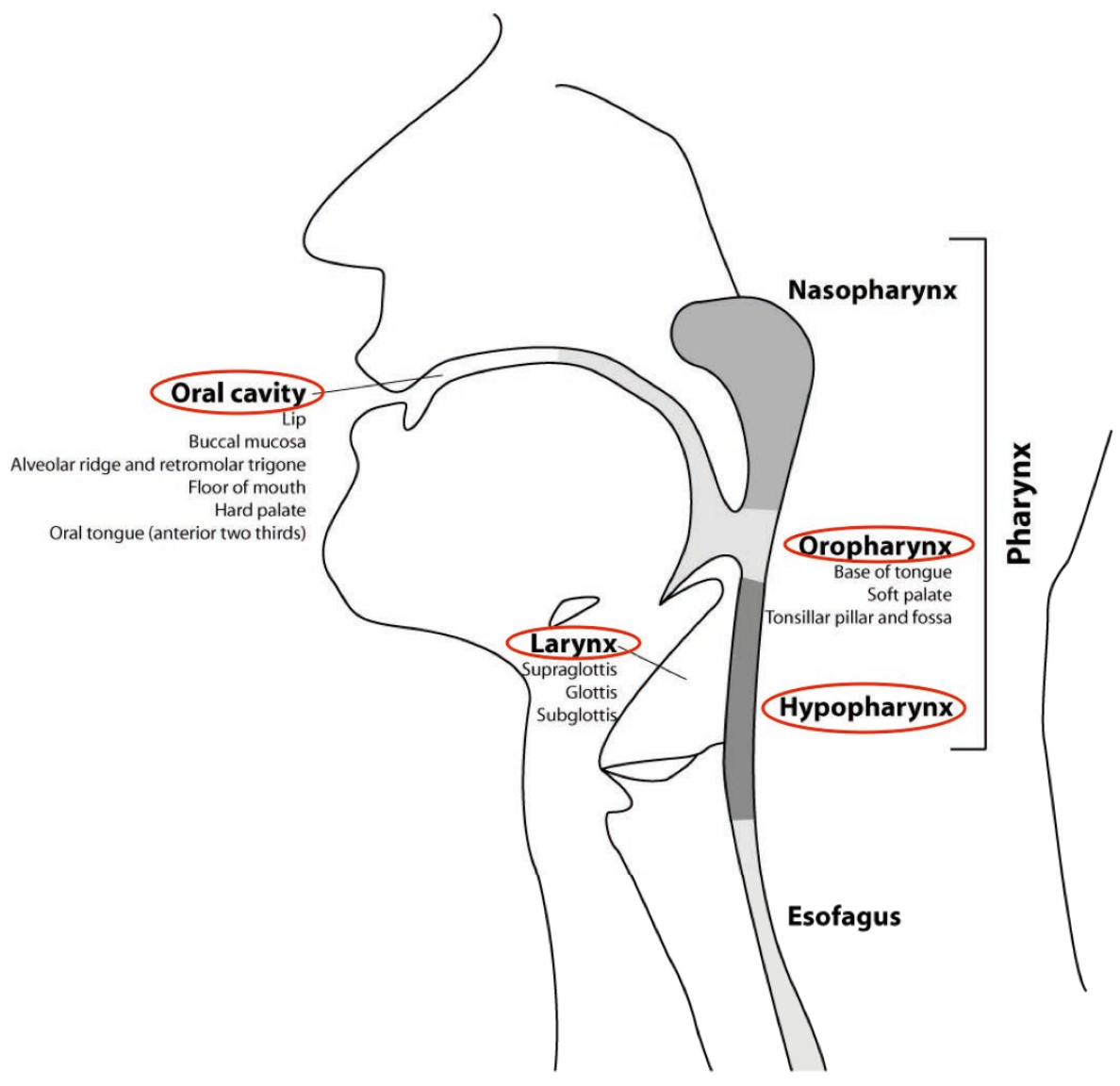

Figure 1. Regions of origin of HNSCC. The highlighted regions are the most common and represent the localization of tumors studied in this thesis.

The sites of the lip, oral cavity, oro-/ hypopharynx, and larynx are most commonly affected and constitute together the seventh most common cancer worldwide. 1,450,000 people are living with the diagnosis HNSCC (5-year prevalence), approximately 600,000 are newly diagnosed every year, and around 325,000 HNSCC-related deaths occur annually (6). Moreover, when including the salivary glands, the nasopharynx, and the upper $2 / 3$ of the esophagus (which are cancers of the upper aerodigestive tract) it becomes the third most common cancer in men, the seventh in women (7). 


\subsubsection{Etiology and risk factors}

Histologically, more than $90 \%$ of head and neck cancers are squamous cell carcinomas originating from epithelial cells of the mucous membrane. Multiple environmental, behavioral, and biological risk factors are involved in the development of HNSCC. The main risk factors are lifestyle-dependent and involve alcohol and various forms of tobacco (smoking or chewing). Those two main risk factors have a known synergetic effect $(8,9)$. Other behavioral risk factors are micronutrient deficiency (=low intake of fresh fruit and vegetables containing antioxidants) (10) and poor oral hygiene $(11,12)$. Viruses constitute the biological risk factors: human papilloma virus (HPV) has been mainly linked to cancer in the oropharynx and tonsils $(13,14)$ and Epstein-Barr-Virus to nasopharynx cancer (15). Environmental risk factors include UV light (especially lip-cancer), in- and outdoor air pollution, and occupational exposures to radiation or chemical carcinogens (inhaling of wood dust, asbestos, manufacturing of textiles and leather)(16).

\subsubsection{The patient}

Traditionally, HNSCC occurs in patients in the fifth decade of life and above, with a higher incidence in men than women and a clear connection to traditional risk factors (alcohol, smoking). However, in recent years there has been a notably increase of HNSCC in patients younger than 40 years $(17,18)$. This development was highlighted by the absence of traditional risk factors in these younger patients and led to the identification of high-risk HPV as a cause of oropharyngeal cancer, and finally to the distinction between $\mathrm{HPV}^{+}\left(\mathrm{HPV}-\right.$ positive) and $\mathrm{HPV}^{-}$ (HPV-negative) oropharyngeal tumors as two clinically different entities (17). $\mathrm{HPV}^{+}$OPSCC (oropharyngeal SCC) is associated with a more aggressive phenotype, but also with a better response to radiotherapy and patient survival compared to $\mathrm{HPV}^{-}$tumors (19). 


\section{INTRODUCTION}

\subsubsection{The symptoms and prognosis}

Depending on the location of HNSCC, symptoms vary and the quality of life in these patients can be highly affected. Symptoms are caused by destruction of the anatomic structures and impairment of the organ functions by tumor growth. For instance, in tongue cancer speech and swallowing are impaired. In larynx cancer, hoarseness and breathing problems occur. Due to tumor growth the symptoms can become life-threatening, for instance by blocking the upper airway or by massive bleeding from large vessels. In the beginning, symptoms can be very subtle and patients often seek medical attention when the tumor has grown into advanced stages. At this time aggressive treatment with harsh side-effects is often unavoidable and the prognosis is poor. Although huge advances have been made in diagnostic techniques and in treatment modalities, the survival rate still lies around $60 \%$.

\subsection{Treatment}

When a patient is diagnosed with HNSCC, the individual's treatment options are discussed by a multidisciplinary board, involving specialists in the fields of ENT, oncology, radiology, and pathology. For decision-making the TNM-classification ( $\mathrm{T}=$ tumor size, $\mathrm{N}=$ nodal status, $\mathrm{M}=$ metastasis; clinically and radiologically determined), the primary site, the histological grade (low, medium, high), and the patient's health status are taken into account. The main standard treatments are surgery and radiotherapy, either alone or in combination. Generally, low stage tumors (stage I-II) are treated with single modality therapy, either surgery or radiotherapy alone, whereas high stage tumors (III and IV) are treated with a multimodality approach including also chemotherapy and molecular targeted drugs (17). Treatment intention is either curative or palliative. In recurrences, the former treatment and the current patient performance status have to be considered in regards to further therapeutic options. Since HPV-status has emerged as an important prognostic marker in HNSCC it now has to be taken into account for treatment decision in oropharyngeal cancer, as de-intensification of treatment might be an option (19). 


\subsubsection{Surgery}

Surgery is the treatment of choice in tumors that are resectable with good tumor-free margins without venturing the organ function severely, e.g. low stage (T1) tongue cancer or glottic laryngeal cancer. Surgical options are open surgery with simple tumor excision and primary wound closure or, in certain cases, secondary wound healing (e.g. in tongue cancer), or advanced excision with reconstruction and local pedicled- or free microvascular flaps. Other surgical options are minimal invasive transoral laser surgery or transoral robotic surgery. Limitations of surgery are the preservation of organ function and avoidance of severe cosmetic deformity. Both impaired organ function (e.g. dysphagia, hoarseness) and cosmetic deformity cause a tremendous decrease in quality of life (17). Another limitation is the relation to surrounding tissue, like perineural or perivascular growth, making the tumor inoperable and oncological treatment the only option.

\subsubsection{Radiotherapy}

Radiotherapy (RT) is the other main treatment regime in HNSCC and is an option both in the curative and palliative setting. In early stage tumors, e.g. laryngeal cancer, tonsil cancer, or tongue base cancer, it can be given as a single therapy, whereas it is part of a multimodality approach in locally advanced tumors (e.g. prior or subsequent to surgery; concurrent with chemotherapy or molecular targeted anticancer therapy). The ionizing radiation induces DNA damages either indirectly by generating free oxygen radicals or by directly interacting with DNA (20). This results in initiation of cellular responses like cell cycle arrest, DNA repair, senescence, apoptosis or mitotic catastrophe, the latter being the major cell death mechanism in solid epithelial tumors (21). The greatest disadvantage and limitation of RT is treatment toxicity. Acute and late side-effects like mucositis, skin rashes, dysphagia, xerostomia, and osteoradionecrosis all cause suffering and reduce quality of life. Therefore the patient's performance status, previous radiation, and the proximity of risk organs to the tumor mass have 


\section{INTRODUCTION}

to be considered thoroughly before a treatment decision is made, as they all play a role in the tolerance of treatment toxicity and grade of acute and late side-effects. Different techniques have been developed to minimize the damage on risk organs and normal tissue. Fractionation of the total dose is based on the fact that normal cells proliferate slower than cancer cells and have time to repair damage before replication (20). Conventional fractionation is given with 2 Gy once daily, 5 days/week for 6.5 weeks with a total curative dose of 68 Gy. Altered fractionation regimes (hyperfractionation, accelerated fractionation) have been developed to increase local control of the tumor with a cost of increased acute toxicity. Several clinical trials have been performed to compare different treatment techniques in locally advanced head and neck cancer (22). Parsons et al concluded that hyperfractionated radiotherapy (a reduced fraction given twice daily in a similar time period with an increased total dose) was superior to conventional RT, with greater acute side-effects but less late side-effects. Accelerated fractionation (AF: two fractions daily, with the same total dose but a shorter delivery period) showed no significant difference regarding locoregional control or survival compared to conventional RT in the 5-year report of the ARTSCAN study (23). Acute morbidity was significantly worse in patients treated with AF but there was no difference in late side-effects (23). Improvements in dose delivering techniques have also been done in regard to sparing risk organs and normal tissue. By intensity-modulated radiotherapy (IMRT), the tumor mass is treated with a higher dose than the healthy surrounding tissues and risk organs, thus minimizing side-effects without venturing treatment outcome (24).

\subsubsection{Chemotherapy}

In HNSCC chemotherapy (CT) is given in combination with radiotherapy, either with or without surgery. The cytostatic drugs are given intravenously and function either by blocking the synthesis of DNA or by attacking the integrity of DNA. Chemotherapy can be given as induction or neoadjuvant CT (= before radiotherapy), as concomitant CT (= at the same time) 
or as adjuvant CT (=after radiotherapy). Given in a neoadjuvant setting, the aim is to shrink the tumor, allowing for easier treatment procedures with surgery or radiation. CT given concomitantly or adjuvantly amplifies the treatment effect, improving locoregional control and patient survival, and decreasing the risk of recurrence. The addition of chemotherapy has been shown to increase survival 4 - 9\%, varying between different tumor sites, the largest effect with concomitant CT $(25,26)$. Concomitant chemoradiotherapy with the platinum-based drug cisplatin is a standard treatment in locally advanced HNSCC. Other cytostatic drugs used in HNSCC are 5- Fluorouracil (5-FU) and taxanes (e.g. docetaxel). The combination of these three drug types are used in induction CT and can be considered in selected patients with a high-risk of distant and local failure $(26,27)$. The limitations of chemotherapy are the severe side-effects (acute and late toxicity) and thus reduced tolerance in elderly patients and in patients with comorbidities.

\subsubsection{Targeted Cancer Therapy}

Targeted cancer therapies use drugs that interfere with specific molecules (=specific targets) involved in cellular processes such as cancer cell proliferation, progression, invasion, and survival. The treatment interference leads to inhibition of cancer growth and spread. Different types of targeted therapies exist, but so far the only FDA-approved targeted cancer therapy in HNSCC is Cetuximab.

\subsubsection{Cetuximab}

Cetuximab is a monoclonal antibody that targets the epidermal growth factor receptor (EGFR). With an approximately 10-fold higher affinity to EGFR compared to endogenous ligands, cetuximab binds EGFR and inhibits activation of EGFR downstream signaling. Moreover, it induces internalization and thereby downregulation of EGFR (28). In in vitro experiments cetuximab has been shown to inhibit cell proliferation and to induce apoptosis as well as to enhance radiosensitivity (29). Since then, cetuximab has become a part of the treatment strategy 


\section{INTRODUCTION}

in patients with locally advanced HNSCC. Given concurrently with radiotherapy it has proven to have beneficial effects compared to radiotherapy alone (30) with an improved overall survival of 20 months. However, cetuximab combined with chemoradiotherapy did not show any beneficial effects compared to chemoradiotherapy alone (31). Riaz, $\mathrm{N}$ et al have compared concurrent cisplatin-RT-treatment to treatment with cetuximab and RT and found superior outcomes for chemoradiotherapy over treatment with cetuximab and RT (32). Side-effects of cetuximab are mainly dermatological (rash, acne) but fever, nausea, and vomiting also occur. Side-effects occur more frequently in combination with RT, most commonly the acneiform rash. Interestingly, the severity of the rash correlates inversely to improved survival, suggesting it as a prognostic marker of favorable outcome (30).

\subsubsection{Dasatinib}

Dasatinib is a tyrosine kinase inhibitor that targets c-Src, a member of the Src-family (= nonreceptor tyrosine kinases). Activation of c-Src mediates transformation, proliferation, invasion, and metastasis in cancer cells. It is overexpressed in HNSCC, and inhibition by dasatinib induced cell cycle arrest and apoptosis in vitro, as well as inhibited migration and invasion (33). Dasatinib is FDA-approved for chronic myeloid leukemia but not yet for HNSCC. A phase II clinical trial has not shown benefit of single treatment with dasatinib in advanced HNSCC (34), but there are data suggesting that the combination of cetuximab and dasatinib may improve the therapeutic effect (35). Moreover, mesenchymal cancer cells have shown greater sensitivity towards dasatinib which opens up for combination treatment possibilities in tumors with EMT-associated resistance (36).

\subsection{Influences on treatment sensitivity}

Hypoxia, epithelial-to-mesenchymal transition (EMT), and cancer stem cells (CSC) are three known factors to influence treatment sensitivity and it has become evident that they are interconnected. Hypoxia has been shown to trigger induction of EMT (37) and to generate CSC 
by hypoxia-induced transcription factors $(38,39)$. Moreover, it has been shown that epithelial cells can gain stem cell properties during EMT (40), facilitating tumorigenic potential and selfrenewal (37). The relation between these three factors is of outmost importance, as they all contribute to treatment resistance. For this reason, a combined approach of several targeting modalities will probably be necessary to improve outcome for the patient.

\subsubsection{Hypoxia}

Hypoxia (=reduced oxygen availability) is a well-established cause for resistance to radiotherapy in solid tumors (41). It arises when an imbalance between oxygen $\left(\mathrm{O}_{2}\right)$ supply and consumption occurs, for instance because of insufficient angiogenesis during rapid tumor growth or dysfunctional and aberrant blood vessels in the tumor. In normal cells, hypoxia usually induces apoptosis and leads to cell death. However, cancer cells can adapt to hypoxic conditions and thereby evade cell death. Oxygen is needed in order to form free oxygen radicals to induce DNA damage and subsequently cell death during radiotherapy $(42,43)$. Without sufficient oxygen levels the effect of radiotherapy is reduced, and the cancer cells in the hypoxic areas survive and continue to grow. A key mediator in the adaption to hypoxia is the transcription factor HIF-1 (hypoxia-inducible factor-1). HIF-1 activates a number of genes involved in angiogenesis, glucose metabolism, cell proliferation and immortalization, processes tightly linked with malignant progression and cancer cell survival. Hypoxic areas $\left(=\mathrm{pO}_{2} \leq\right.$ $2,5 \mathrm{~mm} \mathrm{Hg}$ ) occur frequently in solid tumors (41) and can be determined non-invasively using endogenous biomarkers for hypoxia, e.g. HIF-1 $\alpha$ or CAIX. An association between hypoxia/ HIF-1 $\alpha$ overexpression and treatment resistance/ aggressive tumor phenotype has been observed in HNSCC as well as in many other cancers. $(42,43)$

\subsubsection{Epithelial-to-mesenchymal transition}

EMT is a biological process in which primary epithelial cells lose their characteristic phenotype and function and become either partly or fully mesenchymal (44). During this process they gain 


\section{INTRODUCTION}

mesenchymal functions like the ability to invade and migrate through extracellular matrix (45). This process is physiological during embryonic development and in tissue repair processes. However, it also plays a key role in malignant progression of epithelial cancer by providing means for invasion and metastasis (46). The exact mechanism of how the EMT process is induced is not yet clear but one suggestion is that EMT is initiated upon signaling from surrounding tumor stroma cells (44). Next, the epithelial tumor cells lose their polarization and adhesion to the basal membrane and to adjacent cells. A change in morphology occurs from an epithelial phenotype (cobblestone-like monolayered cell) to a more mesenchymal phenotype (spindle shaped cell), and mesenchymal functions are gained. After the change to a more EMTphenotype the tumor cells can enter the blood circulation and travel to distant sites in the body where they may colonize and form micro- and macro-metastasis. At the end of this process the cells may return to their epithelial phenotype by the inverse process, MET (mesenchymal-toepithelial transition), and thereby resemble the primary tumor they came from (44). Tumors with EMT features have been linked to a more malignant cancer phenotype, in regards to invasion and metastasis, and worse patient outcome. The phenotype of cancer cells can be determined by expression of markers (e.g. transmembrane proteins, various transcription factors). One of the better characterized features of EMT is the loss of epithelial markers (e.g. decreased E-Cadherin expression) and the increase of mesenchymal markers (e.g. increased NCadherin) (37). The loss of E-cadherin is considered a hallmark for EMT and is used as a marker for EMT in head and neck cancer (47). Activation of transcription factors such as Snail or Slug, which activate mesenchymal markers and represses epithelial markers, can also be observed and plays an important role for EMT induction (37). EMT has been associated with chemoradio-resistance in several cancers including $\operatorname{HNSCC}(48,49)$. The induction of EMT activates genes involved in inhibition of apoptosis and enhancement of cell survival, resulting in cell death evasion and thereby treatment resistance (37). Examples of protein markers that have 
been associated with treatment resistance and poor prognosis are Twist, Vimentin, Fibronectin, Snail, Slug, FOX1, N-cadherin among others (50-55).

\subsubsection{Cancer stem cells}

The theory of CSC in solid tumors is based on tumor heterogeneity, meaning that a tumor consists of subpopulations of cells with divergent phenotypes and with different proliferative potentials (56). Cancer stem cells are a subpopulation of tumor cells that are undifferentiated, have the ability to self-renew and to induce new tumor growth (= tumorigenic cells). The existence of CSC in solid tumors has been suggested to be a cause for treatment resistance and relapses. An explanation is that the current treatments kill a majority of cells and lead to shrinking of the tumor, but might fail to kill CSCs that remain and initiate regrowth of the tumor (56). CSCs in solid tumors may be identified by detection of cell surface markers. This has been successfully done in breast cancer (56) where high expression of the cell surface protein CD44 and low or no expression of CD24 was observed in a small group of tumorigenic cancer cells. In HNSCC, Prince et al showed in cells from primary HNSCC samples that CD44-high but not CD44-low cells gave rise to tumors in mice (57). Furthermore, in HNSCC cell lines, populations with higher expressions of CD44 and CD133 have been identified and these populations have demonstrated a high tumorigenic potential when inoculated in mice (58).

\subsection{Personalized medicine}

The term personalized medicine has evolved out of the observation that there are inter patient differences in treatment response. In a population of patients with the same diagnosis and the same treatment, some are treated very successfully, some have no treatment effect at all, and others actually get significantly worse during the course of the given treatment (e.g. tumor growth, side-effects). Increased understanding of tumor biology has revealed underlying genetic and molecular differences between tumors of the same histologic type. In personalized medicine we aim to find markers that help us to distinguish patients who will benefit from a 


\section{INTRODUCTION}

planned treatment and patients who might be harmed, and subsequently tailor the treatment to the individual patient. Treatment advances have been made in all treatment modalities in HNSCC, as described above. Modern imaging and surgical tools make it possible for the surgeon to excise tumors in a more refined way and even excise those tumors that earlier would have been classified as inoperable. In radiotherapy, new fractioning schedules and volume measuring have made it possible to aim different doses to defined target volumes, so that the side-effects can be minimized and normal tissue better spared. Even new treatment modalities like molecular targeted cancer drugs have arisen and are used in patients with locally advanced cancer. Still, the success rate measured in survival and recurrences is unsatisfactory, and the differences in treatment-response of patients with the same tumor classification constitute a big problem. Personalized medicine might be the solution. However, in order to achieve personalized medicine, predictive biomarkers of treatment response are needed.

\subsection{Biomarkers}

Biomarkers are biological factors that can be measured accurately and reproducibly, and are related to biological and pathogenic processes and/or to response to treatment. In cancer, biomarkers can be prognostic, providing insight into likely outcome for the patient, independent of treatment, or predictive, helping us to predict response to a specific treatment (59). The identification of prognostic and predictive biomarkers is crucial in order to develop individually tailored treatment plans and may potentially lead to the development of new therapeutic strategies.

\subsubsection{How to find biomarkers for cancer}

Cancer arises from one single cell and develops progressively in multiple steps over a long time. Chronic exposure to carcinogens, molecular and genetic alterations (DNA structure, tumor suppressor genes or oncogenes) and evasion of various defense mechanisms build the grounds for cancer transformation. Through molecular mapping of cancer, alterations in genes 
important in processes such as cell cycle regulation, cell death pathways, and DNA repair have been identified. Hanahan and Weinberg have defined in their „Hallmarks of cancer“(46, 60), a list of capabilities that a cell has to obtain in order to undergo transformation to cancer (Figure 2).

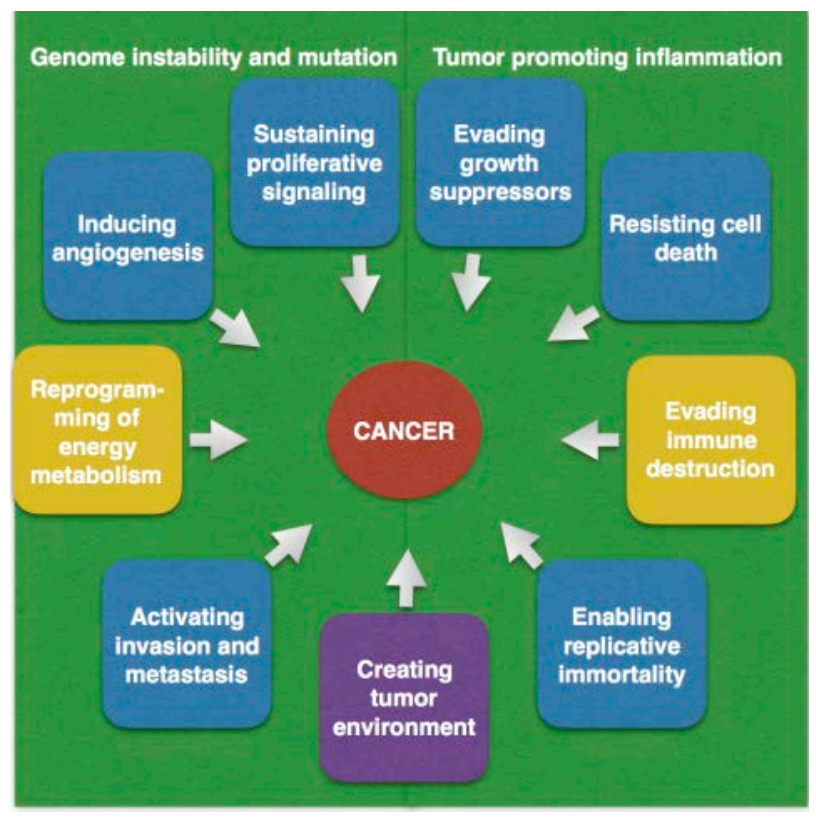

Figure 2. Modified from "Hallmarks of Cancer" (60). Categories as denoted by Hanahan and Weinberg: blue: acquired hallmarks of cancer; yellow: emerging hallmarks; purple: importance of the tumor microenvironment, green: enabling factors.

When in search for cancer biomarkers it makes sense to investigate factors involved in these processes. In this thesis we have focused on a number of processes and factors involved in the "hallmarks of cancer" and investigated their potential as cancer biomarkers (Figure 3). 


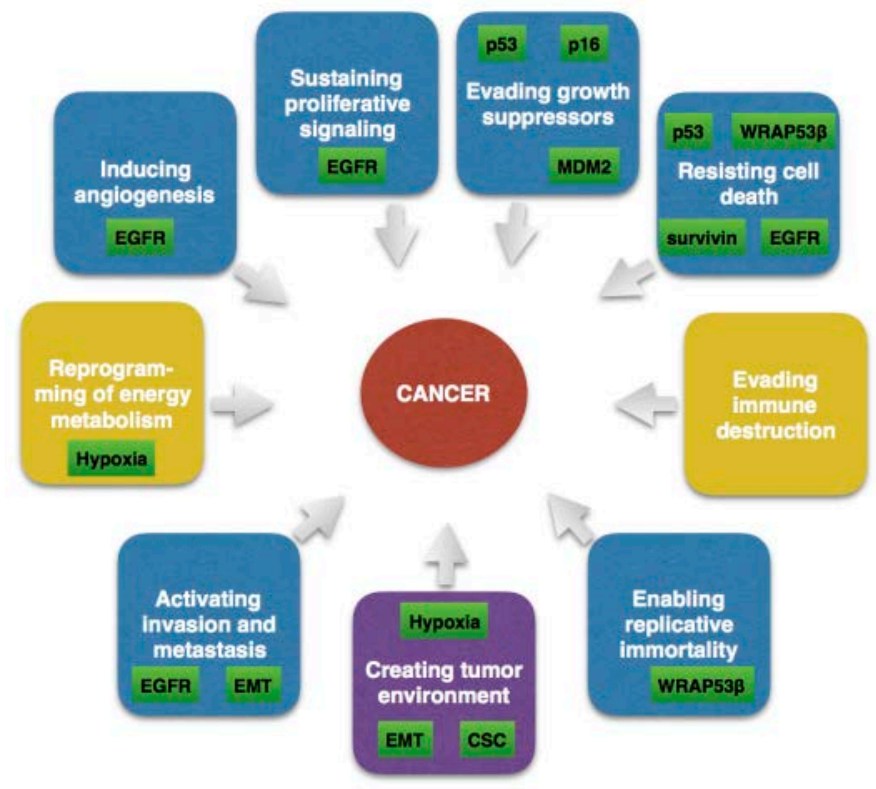

Figure 3. Processes and factors investigated in this thesis in relation to the hallmarks of cancer.

\subsubsection{Specific biomarkers}

\subsubsection{Survivin}

Survivin is the smallest member of the Inhibitor of apoptosis protein (IAP) family. It is commonly expressed in embryonic and fetal tissue, can sometimes be found in proliferating adult tissue, but is rarely detected in terminally differentiated normal tissue. However, overexpression of survivin is well documented in the most common human malignancies (61) and is correlated to tumor progression and treatment resistance (62). Several studies have investigated survivin's role in HNSCC, with contradicting results (63). Survivin was shown to correlate with a more aggressive phenotype and worse survival in SCC from different head and neck subsites (64-66). On the other hand there are studies that have shown a favorable outcome associated with high survivin expression in oral SCC $(67,68)$. New therapeutic strategies targeting survivin have been developed and have reached phase II trials $(69,70)$. 


\subsection{Survivin biology}

Survivin has both anti-apoptotic and pro-mitotic functions, related to its subcellular localization and regulated by posttranslational modification mechanisms like phosphorylation and acetylation (Figure 4).
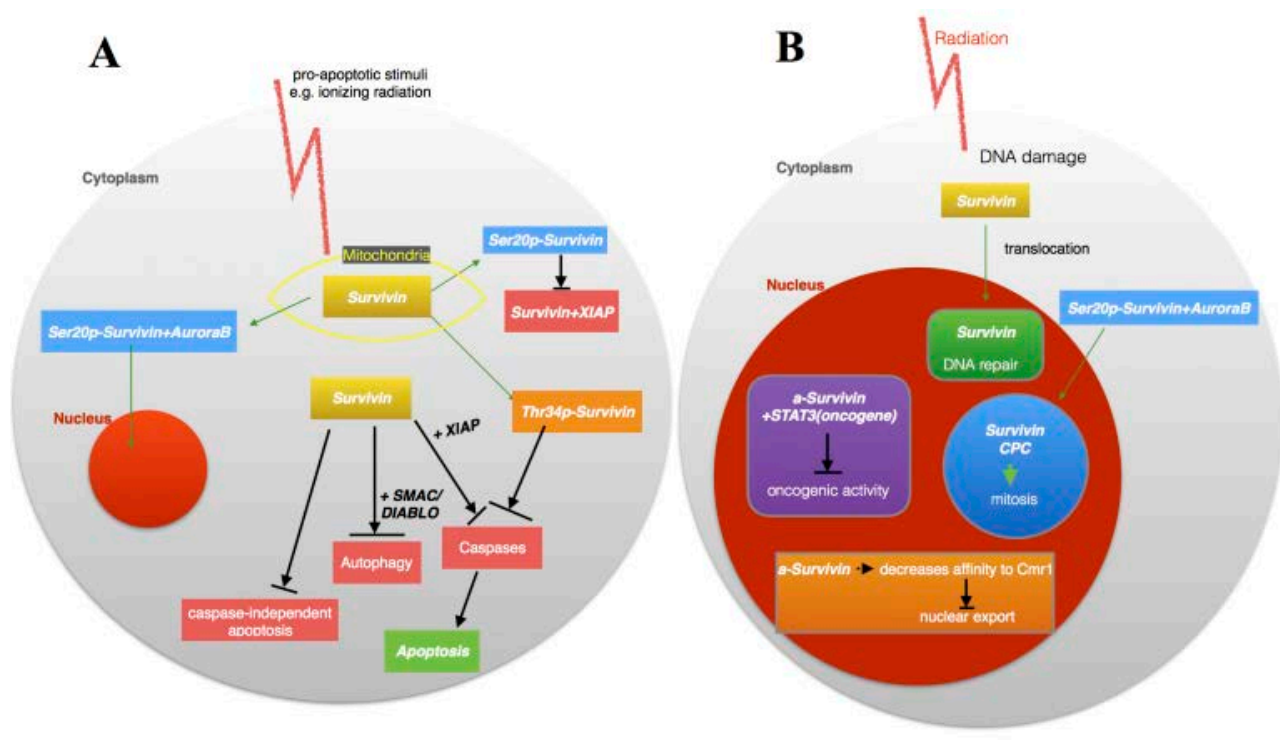

Figure 4.. The functions of survivin shown in relation to its subcellular localization, A) in the cytoplasm, B) in the nucleus. Adapted from (62) and modified.

Predominantly located in the cytoplasm and mitochondria, survivin inhibits cell death mechanisms. First, it can block apoptosis either by indirect binding of caspase-9 via XIAP (Xlinked inhibitor of apoptosis protein) or by direct binding to caspases 3/7 (70). Phosphorylation of survivin at Thr34 also blocks apoptosis $(62,70)$. Binding and thereby inhibiting the proapoptotic protein SMAC/DIABLO (Secondary Mitochondria- derived Activator of Caspase) results in inhibition of autophagy. By this means, cytoplasmic survivin acts cytoprotectively. However, the complete mechanism of inhibition of apoptosis by survivin is not fully known (69). Due to its low molecular weight survivin can enter the nucleus by passive diffusion (71) where it together with Aurora B (a mitotic kinase), Borealin, and INCENP (inner centromere 


\section{INTRODUCTION}

protein) forms the mitotic key regulator protein CPC (chromosomal passenger complex) (72). Through this pathway survivin may affect the regulation of mitotic spindle formation and cytokinesis, representing its pro-mitotic function and involvement in cell progression. Ser20phosphorylation of survivin in the cytoplasm enhances binding to Aurora B kinase, contributing to the formation of the CPC and thereby also acting pro-mitotically. In contrast, Ser20phosphorylation of survivin attenuates its anti-apoptotic activity by interfering with the binding of survivin to XIAP (62). This illustrates the significance of posttranslational modifications in survivin functions. However, the nuclear export of survivin is not passive but actively regulated by binding survivin via its NES (nuclear expert signal) to a nuclear export receptor, the Crm1 (chromosome region maintenance-1) (72). Acetylation of nuclear survivin leads to decreased affinity to Crm1, resulting in nuclear accumulation of survivin, followed by decreased presence in the cytoplasm and increased apoptotic activity (62). Additionally, acetylated survivin also interacts with the oncogene STAT3 (signal transducer and activator of transcription 3), suppressing its oncogenic activity. Thus, nuclear acetylated survivin seems to inhibit cell survival. On the other hand, nuclear survivin has also been shown to play a role in DNA damage repair by enhancing repair capacity (70). The existence of different splicing variants may also play a role in survivin function. Wild type survivin, deltaEx3 (loss of exon 3 ) and $2 b$ (inclusion of exon $2 \mathrm{~b}$ ) are the most researched in association with cancer (69). However, their contribution to tumor progress, tumor behavior, and treatment response is not completely understood and needs to be investigated further (69). 


\subsubsection{WRAP53}

WRAP53 (WD40 encoding RNA Antisense to p53) is a relatively recently discovered gene which has been linked to the pathogenesis of diseases like spinal muscular atrophy (SMA) (73) and dyskeratotis congenita (74), as well as to multiple forms of cancer. Increased levels of the protein WRAP53 $\beta$ have been demonstrated in cancer cell lines as compared to normal cells (75), and overexpression of WRAP53 $\beta$ has been linked to poor outcome in patients with HNSCC (75) and in patients with rectal cancer (76).

\subsection{WRAP53 biology}

WRAP53 is a natural antisense transcript to p53, meaning that, located on the opposite DNA strand, it overlaps p53 in a head-to-head fashion and is transcribed in the opposite direction in relation to $\mathrm{p} 53$. Due to variant start exons $(\alpha, \beta, \gamma)$, three alternative transcripts of WRAP53 with divergent functions exist: WRAP53 $\alpha$, WRAP53 $\beta$, and WRAP53 $\gamma$ (function for the latter is yet unknown) (Figure 5).

WRAP53 $\alpha$ acts as a regulator for the tumor suppressor gene p53, both on the mRNA and the protein level, enhancing its induction and stabilization upon DNA damage. The exact mechanism as to how it regulates p53 remains yet unclear (77).

WRAP53 (also called WDR79 or TCAB1) is not involved in p53 regulation. Nonetheless, it has emerged as a significant factor in tumorigenesis due to its crucial role in processes like telomere elongation, Cajal body maintenance, and DNA damage repair (78). 


\section{INTRODUCTION}

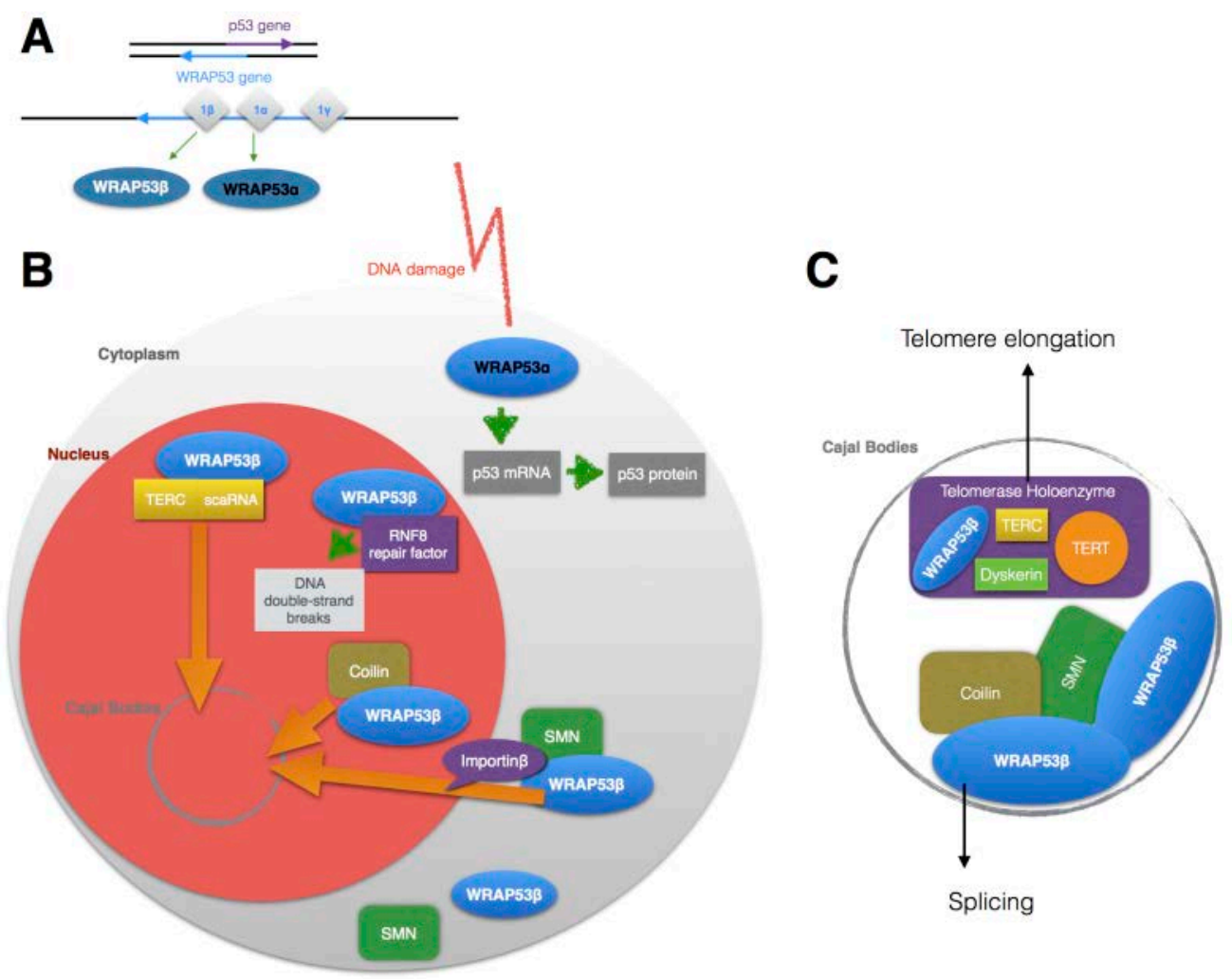

Figure 5. A) The transcription of WRAP53 gene in an antisense fashion to $p 53$ and the gene products of WRAP53. B) The functions of WRAP53 $\alpha$ and $\beta$ (78). C) The role of WRAP53 $\beta$ in Cajal bodies.

In this study we focused only on this WRAP53 variant. Due to its WD-40 domain, WRAP53 $\beta$ acts as a scaffold protein. The WD40-repeats allow WRAP53 $\beta$ to facilitate interaction with multiple proteins simultaneously, making it possible for WRAP53 $\beta$ to execute multiple functions independently of each other (78). One main function is the maintenance and stabilization of Cajal bodies. Cajal bodies are dynamic nuclear structures that enhance essential biological processes in the cell by assembling the necessary factors in the same space. This includes processes like ribonucleoprotein (RNP) maturation, spliceosome formation, and telomere elongation. WRAP53 $\beta$ is crucial for the structural integrity of Cajal bodies. It guides the SMN (survival of motor neuron) protein and coilin to the Cajal bodies and stabilizes interactions between them. Downregulation of WRAP53 $\beta$ leads to failed localization of these 
proteins and subsequently to the collapse of Cajal bodies (73). Defects in Cajal bodies lead to impaired cell proliferation and splicing rates (73). The SMN protein, a splicing regulatory protein, is involved in the assembly of snRNP (small nuclear ribonucleoprotein) in the cytoplasm. snRNPs compose the spliceosome which catalyzes the splicing process. Cytoplasmic WRAP53 $\beta$ directs SMN from the cytoplasm to the nucleus by promoting its binding to importin $\beta$. In the nucleus, WRAP53 $\beta$ guides SMN and snRNP to the Cajal bodies, building a scaffold and assuring their function in the splicing process. WRAP53 $\beta$ also guides scaRNAs (small Cajal body-specific RNA) to the Cajal Bodies (78).

WRAP53 $\beta$ is also important for telomere elongation and telomerase trafficking (79), one of the hallmarks of cancer (60). Telomeres exist at the end of chromosomal DNA, protecting it. They shorten progressively during the cell's lifetime and when largely eroded induce senescence or crisis, ultimately leading to cell death. Therefore, in order to gain unlimited proliferation cancer cells have to overcome telomere shortening. Telomerase exists rarely in normal somatic cells, but may be highly expressed in cancer cells. TERC (telomerase RNA component) is a member of the scaRNA family. Together with the telomerase reverse transcriptase (TERT), dyskerin and WRAP53 $\beta$, TERC constitutes the telomerase holoenzyme that adds telomere repeats to the telomeric DNA, counteracting telomere shortening and thereby cell death $(75,79)$.

WRAP53 $\beta$ is also involved in DNA damage response and repair (80). It acts as a scaffold for DNA repair proteins and stabilizes interactions between them at the site of DNA double strand breaks (80). The subcellular localization has been suggested to form the basis for normal function of WRAP53 $\beta(81)$. It is localized both in the cytoplasm and the nucleus. Little is known about the subcellular trafficking mechanisms of WRAP53 $\beta$, but it is suggested that deviant localization may cause dysfunction of WRAP53 $\beta$. 


\section{INTRODUCTION}

\subsubsection{HPV and p16 ${ }^{\mathrm{INK} 4 \mathrm{a}}$}

HPV has emerged as an important risk factor for HNSCC. Overall, there are approximately 179 genotypes, classified in regard to the tissue type that they infect (cutaneous or mucosal), and to the risk for malignant transformation of the host cells (low, medium, high) (19). HPV types 16 and 18, belonging to the mucosal and high-risk subgroup, are relevant in HNSCC. HPV-16 has been shown to play a role primarily in oropharyngeal cancer, whereas HPV-18 is more often found in oral or laryngeal SCC (13). $\mathrm{HPV}^{+} \mathrm{HNSCCs}$ are nowadays recognized as a different entity of tumors compared to $\mathrm{HPV}^{-} \mathrm{HNSCCs}$, regarding both the etiology, tumor behavior, clinical characteristics and prognosis. $\mathrm{HPV}^{+} \mathrm{HNSCC}$ patients are often younger and lack other risk factors. $\mathrm{HPV}^{+} \mathrm{HNSCC}$ is often a more aggressive type of cancer with a higher incidence of regional metastasis, but patients in this group have a better prognosis as compared to those with $\mathrm{HPV}^{-} \mathrm{HNSCC}$. HPV-16 accounts for approximately $80 \%$ of $\mathrm{HPV}^{+} \mathrm{HNSCCs}$ and is associated with a better prognosis than tumors positive for other HPV-suptypes and HPV-

negative tumors (19). The protein $\mathrm{p} 16^{\mathrm{INK} 4 \mathrm{a}}$ (referred to as $\mathrm{p} 16$ ) is used as a surrogate marker for HPV, especially in oropharyngeal SCC, where studies have shown strong correlations between HPV-infection and p16 overexpression (82). Detection of p16 can easily be done by immunohistochemistry. In this thesis the HPV status was investigated by analyzing p16 expression in tumor biopsies obtained before treatment.

\subsubsection{1 p16 biology}

p16 belongs to the INK4 class cell cycle inhibitors. In normal cells it facilitates the binding of $\mathrm{pRb}$ (Retinoblastoma protein) to the transcription factor E2F, resulting in cell cycle arrest and subsequent decrease of p16 expression. Without $\mathrm{p} 16, \mathrm{pRb}$ does not bind to E2F and cell cycle progression and mitosis occur, leading to an increase of $\mathrm{p} 16$. In this manner $\mathrm{p} 16$ expression is regulated by its own feedback mechanism, maintaining the balance between mitosis and cell cycle arrest. In HPV-infected cells however, the HPV DNA encodes for the oncogene E7 that 
binds and inactivates $\mathrm{pRb}$, blocking the binding to $\mathrm{E} 2 \mathrm{~F}$, resulting in continuous cell cycle progression and overexpression of p16 (Figure 6).

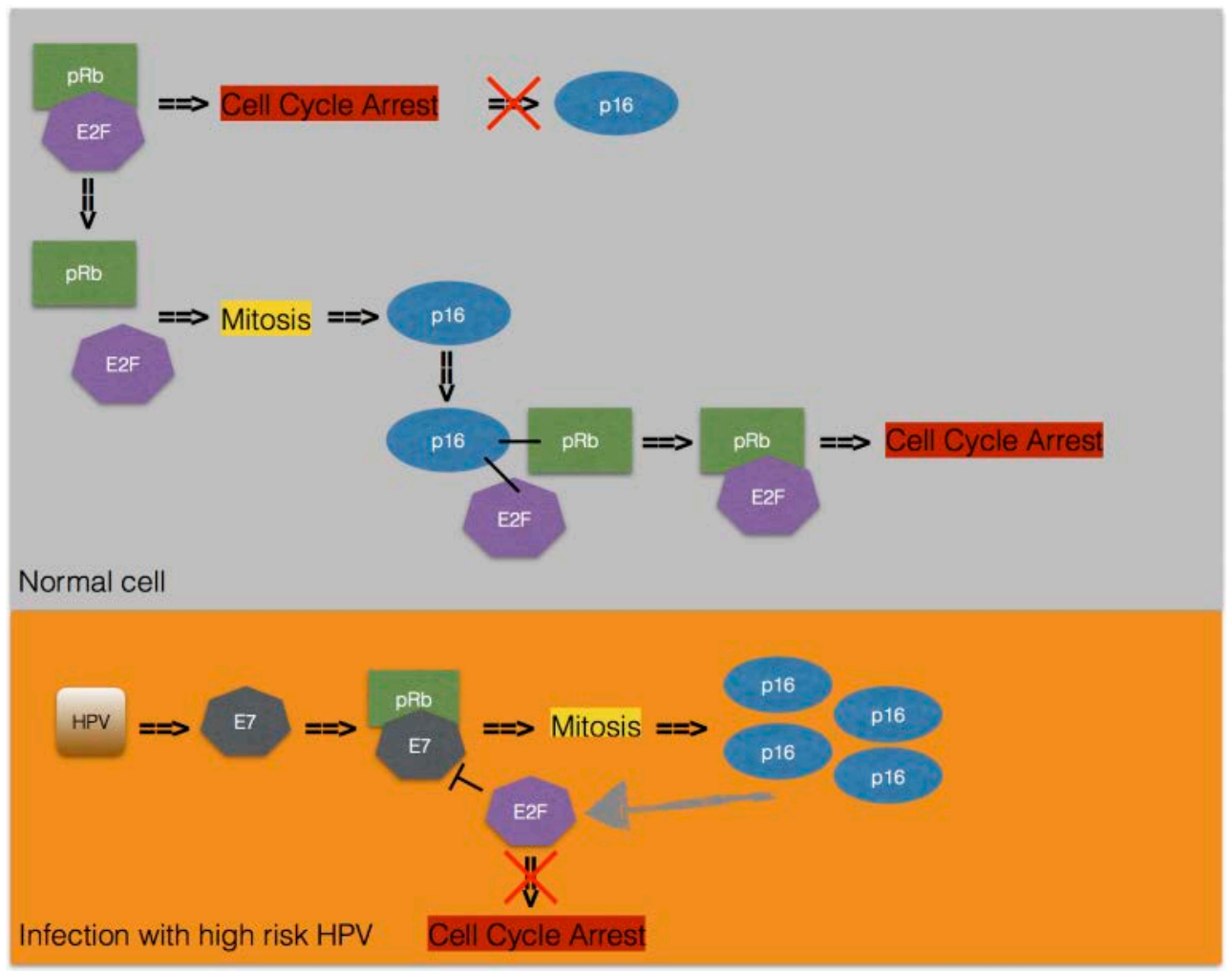

Figure 6. The relationship between high-risk HPV-infection and p16 overexpression.

The oncogene E7 acts differently in low-risk HPV than in high-risk HPV, making p16 overexpression a sensitive marker for high-risk HPV infections (82).

\subsubsection{EGFR}

The epidermal growth factor receptor (EGFR), a member of the ErbB-family, is a transmembrane tyrosine kinase receptor, primarily found in cells with epithelial origin. Upon ligand binding to EGFR, several downstream pathways are activated regulating important cellular processes including cell proliferation, cell survival, apoptosis, cell motility, adhesion, cell differentiation, and angiogenesis (83). EGFR is frequently overexpressed in cancers with 


\section{INTRODUCTION}

epithelial origin. In HNSCC, overexpression is found in up to $90 \%$ (84) and is associated with a more aggressive tumor phenotype, poorer prognosis, and resistance to treatment (85). EGFR is a target for anti-cancer drugs used in the treatment of advanced HNSCC (see section 1.2.4.1). As described earlier, cetuximab blocks EGFR and hinders downstream activation. EGFR is a monomer in its inactive form. Upon ligand binding it forms an active homodimer (with another EGFR molecule) or heterodimer (with another member of the ErbB-family), thereby activating the intracellular protein-tyrosine-kinase (86). Autophosphorylation of tyrosine residues occurs, eliciting activation of several downstream pathways: 1. JAK/STAT: resulting in cell proliferation and cell survival; 2. PI3K/Akt: resulting in angiogenesis, tumorigenesis, and inhibition of apoptosis; 3. Ras/MAPK/ERK: stimulating cell motility, gene expression, and cell-cycle progression; and 4. PLC $\gamma / \mathrm{PKC}$ : resulting in cell cycle progression, transformation, differentiation and apoptosis (87). There is considerable cross talk between the pathways which may also be activated in an EGFR-independent manner. Thus, it is obvious that resistance to cetuximab may have several different underlying mechanisms. In paper IV we investigated the impact of hypoxia and cetuximab in some of these pathways. It has been postulated that HIF$1 \alpha$ is an effector molecule in EGFR-signalling pathways, especially the PI3K/Akt pathway. Inhibition of PI3K by cetuximab led to decreased levels of HIF-1 $\alpha$ by blocking HIF-1 $\alpha$ synthesis, resulting in improved intrinsic sensitivity (88).

\subsubsection{HIF-1 $1 \alpha$}

HIF-1 is a heterodimeric transcription factor that consists of two subunits: the oxygen dependent HIF-1 $\alpha$ and the nuclear HIF-1 $1 \beta$. Under normoxic conditions HIF-1 $\alpha$ is rapidly marked for degradation whereas it eludes degradation in hypoxic conditions and is translocated into the nucleus where it binds to HIF- $1 \beta$ and forms the transcription factor HIF-1. HIF-1 binds consequently to hypoxia response elements (HRE), activating genes involved in processes that ultimately lead to adaption to hypoxia $(41,42)$. HIF-1 $\alpha$ can be detected by 
immunohistochemistry and may be used to study hypoxia in tumors. HIF-1 $\alpha$ overexpression is common in many malignancies and correlates to tumor progression and invasiveness (89). Several studies have shown negative correlations of HIF-1 $\alpha$ with outcome and tumor phenotype in HNSCC (reviewed by Swartz et al, (42)). Sasabe et al showed an association between increased HIF-1 $\alpha$ expression in OSCC and resistance to radio-chemotherapy as well as a more aggressive tumor phenotype (43). In this thesis we analyzed the association of HIF-1 $\alpha$ expression in tumor cell lines to differences in phenotype and treatment sensitivity between cells cultured under normoxic and hypoxic conditions (paper IV).

\subsubsection{6 p53}

TP53 is a tumor suppressor gene mutated in more than $50 \%$ of human cancers (90). Normally, TP53 encodes for the protein p53 that has a short half-life in normal cells. However, upon DNA damage (e.g. radiation-induced) p53 is stabilized and induces cell-cycle arrest to permit DNA repair to take place, or induces apoptosis in cells that cannot be repaired (91). However, mutated TP53 can encode for a dysfunctional protein that lacks tumor suppressive activity, leading to inadequate DNA-repair and apoptosis evasion. In HNSCC the presence of TP53 mutation was shown to be correlated with decreased overall survival (92).

\subsubsection{Single Nucleotide Polymorphisms}

The most common genetic variation among people are so-called single nucleotide polymorphisms (SNPs). They are DNA-sequence variations that differ by a single nucleotide pair between individuals of a population, meaning (at least) one nucleotide (allele) has changed on a certain position in the genome sequence. $99.6 \%$ of the human genome sequence is identical in all human beings. The remaining $0.4 \%$ consists of SNPs that make each and every one unique. Those SNPs can change the phenotype of a person and can also be responsible for development and susceptibility to diseases. To be defined as a SNP the variant allele must exist at a single base pair position within the genomic DNA in at least $1 \%$ of the normal population 


\section{INTRODUCTION}

(93). SNPs are used in medicine as genetic markers to track genes involved in common diseases such as diabetes, cardiovascular disease, mental illness, and cancer. They are also believed to influence not only the frequency of cancer in a population and the onset of cancer in an individual, but also the response to anti-cancer treatments. In paper I, we investigated the association of the following SNPs with radiotherapy response: XPC Ala499Val, XRCC3 Thr241Met, XPD Lys751Gln, XRCC1 Arg399Gln and FGFR4 Gly388Arg, MDM2 SNP 309, p53 Arg72Pro. In paper II, two SNPs in the WRAP gene (rs2287499 and rs2287498), linked to susceptibility to cancer in previous studies $(94,95)$, were investigated in the setting of HNSCC.

\subsection{SNPs in DNA repair genes XPC, XPD, XRCC1, and XRCC3}

Previous studies have shown a relationship between SNPs in DNA repair genes and outcome of radiotherapy (96). Xeroderma pigmentosum complementation group $C$ and $D$ (XPC and $X P D)$ are proteins involved in the identification of DNA damage and initiation of repair. Both the hetero- and homozygous variant genotypes of the XPC Ala499Val SNP were previously found to be significantly associated with less radiation-induced DNA damage than the wild type (97). The X-ray repair cross-complementing group 1 and 3 (XRCC1 and XRCC3) proteins also play important roles in DNA repair and preclinical studies have shown a significant association between the XRCC3 Thr241Met polymorphism and radiotherapy response (98).

\subsection{FGFR4 Gly388Arg}

FGFR4 belongs to the receptor tyrosine kinase family and ligand binding leads to cell growth, mitosis, and differentiation. About $50 \%$ of the population seem to have the FGFR4 Gly388Arg polymorphism (99) that has been linked to aggressive tumor progression and metastasis, and is associated with poor prognosis in $\operatorname{HNSCC}(100,101)$.

\subsection{MDM2 SNP309 and p53 Arg72Pro}

MDM2 (murine double minute 2) is an oncogene and functions as a negative regulator of p53. Overexpression of MDM2 inhibits p53 function, consequently damaged cells can escape cell 
cycle checkpoints and become carcinogenic (102). Polymorphisms in the MDM2 gene can alter the balance between MDM2 and p53 and thereby lower the apoptotic response of the cells and make them more resistant to treatments that depend on apoptosis for cell death. The MDM2 SNP 309 has been associated with poor therapeutic response and poor outcome in HNSCC patients (103). The same results were found for p53 SNP p53 Arg72Pro (103). 



\section{AIMS OF THE THESIS}

The general aim of this thesis was to explore potential predictive and/ or prognostic biomarkers on the protein and gene level in tumor biopsies and cell cultures of HNSCC. Further, we aimed to investigate the role of hypoxia in treatment sensitivity.

The specific aims of the studies were as follows:

I. To examine a series of proteins and SNPs in HNSCC tumor biopsies in order to investigate their potential value as predictive markers of radiotherapy response.

II. More specifically, to investigate WRAP53 $\beta$ and two SNPs of the WRAP53 gene in HNSCC tumor biopsies and to further examine WRAP53 $\beta$, survivin, and p $16^{\mathrm{INK} 4 \mathrm{a}}$ in a larger study cohort of glottic 1SCC.

III. To investigate the impact of hypoxia and the role of HIF-1 $\alpha$ on treatment response, EMT profile, and the expression of CSC markers in HNSCC cell lines. 



\section{MATERIAL AND METHODS}

\subsection{Tumor material}

\subsubsection{HNSCC biopsies}

Tumor biopsies used in papers I, II, and III were obtained from the established tumor collection at the Department of Otorhinolaryngology, Head and Neck Surgery, at the University Hospital of Linköping, Sweden (No 416, The National Board of Health and Welfare in Sweden; approved by the Ethical Committee of Linköping). The tumor collection currently consists of more than 300 tumor biopsies from patients with HNSCC, with ongoing collection since December 2003. After written consent from the patient, an ENT Head and Neck surgeon takes a tissue sample from the tumor in conjunction with diagnostic biopsy procedures at the ENT clinic which means that tumor samples are obtained prior to any treatment. The fresh biopsies are transported to the laboratory where they are registered and processed. One part of the biopsy is immediately frozen in liquid nitrogen and thereafter stored in $-70^{\circ}$ for later use (e.g. DNA analysis). Other parts of the biopsy are used to establish cell lines and/or are formalin-fixed and paraffin-embedded depending on the size of the biopsy.

\subsubsection{HNSCC cell lines}

In study I, II, and IV we used HNSCC cell lines established from biopsies in the Linköping tumor collection. Those cell lines have the prefix LK. In study IV we also used HNSCC cell lines from Turku University, Finland, provided by Professor Reidar Grenman. Those cell lines are named with the prefix UT-SCC.

Established LK cell lines were cultured in Keratinocyte-serum free medium (SFM) supplemented with penicillin, streptomycin, and 10\% fetal bovine serum (FBS). Fresh medium was given twice a week, and the cells were subcultured at confluence once weekly. Periodical screening for mycoplasma contamination was performed. The UT-SCC cell lines were cultured 
in Dulbecco's Modified Eagle's Medium (DMEM), supplemented with glutamine, penicillin, streptomycin and FBS. In paper IV cells were cultured in hypoxia $\left(1 \% \mathrm{O}_{2}\right)$ to investigate the effect of hypoxia on treatment sensitivity.

\subsubsection{Patient data}

All data related to the patients and their cancer was collected from the patients' medical charts from the department of Otorhinolaryngology, Head and Neck Surgery at the University Hospital of Linköping, transferred to the registry of the tumor collection, and linked to the obtained tumor sample. The registry is updated regularly and includes patient characteristics (age, gender, date of diagnosis, smoking habits etc.), tumor characteristics (tumor site, TNMclassification, histological grade etc.) and information about treatment and follow-up. Data for tumor biopsies from Helsinki and Karolinska were also linked to similar registers and obtained thence.

\subsubsection{Papers I and II}

A retrospective cohort of tumor biopsies were gathered from the Linköping tumor collection, including patients diagnosed with HNSCC from 2003 to 2009. The inclusion criterion was treatment with radiotherapy, either as a single treatment or combined with surgery. According to the treatment response, patients were grouped into Non-responders or Responders. The treatment response was determined clinically by an experienced ENT Head and Neck surgeon and the information was obtained retrospectively from the medical charts. A Non-responder was defined by either having a growing tumor during radiation, a remaining residual tumor after radiation, or relapse within 6 months of radiotherapy. A Responder was defined by tumor size reduction during radiotherapy and no sign of relapse within one year after irradiation. Twenty individuals were identified for the Non-responder group whereafter twenty Responders were selected, matched according to tumor localization and histological grade as closely as possible. 
The cell lines LK0412 and LK0949 were used for siRNA transfection. Both cell lines are derived from fresh tongue tumor samples. Cells in passages 12-18 were used.

\subsubsection{Paper III}

149 tumor biopsies of patients with glottic laryngeal squamous cell carcinoma (glSCC) without metastasis classified as T2-T3N0 and with radiotherapy or radiochemotherapy as primary treatment during 1999-2009 were gathered from the archives of Linköping University Hospital $(\mathrm{n}=10)$, University Hospital of Helsinki $(\mathrm{n}=64)$, and Karolinska University Hospital $(\mathrm{n}=75)$.

\subsubsection{Paper IV}

The cell lines LK0412 (tongue), LK0827 (tongue), LK0923 (larynx), UT-SCC-2 (floor of mouth) and UT-SCC-14 (tongue) were used. The cell lines were selected according to their phenotype (epithelial: LK0412, UT-SCC-2, UT-SCC-14; or mesenchymal: LK0827, LK0923) and their known intrinsic sensitivity for radiation, cisplatin, and cetuximab. Passages from 1025 were used.

\subsection{Immunohistochemistry}

Immunohistochemistry (IHC) detects specific cellular components (e.g. proteins) in a tissue sample by visualizing an antigen-antibody reaction. After pretreatment of a formalin-fixed, paraffin-embedded tissue sample with a buffer (to unmask antigen epitopes), endogenous peroxidase is blocked and thereafter a solution with a primary antibody targeting the desired antigen (e.g. the specific protein) is added which binds specifically to the antigen under investigation. After a wash step, a secondary antibody targeting the primary antibody is added. The secondary antibody is labeled with a tracer enzyme, e.g. a horseradish peroxidase enzyme that transforms chromogen into a brown-colored precipitate that accumulates at the site of reaction, thereby visualizing the localization of where the first antibody is bound, and consequently where the targeted antigen is located. Counterstaining with hematoxylin is 


\section{MATERIAL AND METHODS}

performed for morphologic evaluation. The chromogenic stains can then easily be observed in a light-microscope, the staining pattern revealing information about the protein expression and localization of the investigated protein.

Immunohistochemistry is commonly used to identify specific biomarkers, both in clinical routine and in cancer research. It is a comparably cheap method and widely used in diagnostics in the pathology clinic. Antibodies are commercially available and come with a procedure protocol to facilitate uniform and reproducible analysis. Automated immunohistochemistry also increases the reproducibility and reliability.

\subsubsection{Scoring system for IHC analysis}

For established biomarkers there are validated scoring systems, e.g. the Hercep Test for HER2protein expression (104). However, many experimental biomarkers lack validated scoring systems resulting in multiple studies with divergent scoring methods. The most common way of assessing expression of biomarkers by IHC is by scoring both the percentage of positively stained cells in relation to the total number of tumor cells (quantitative/semi-quantitative assessment of positively stained cells) and the staining intensity (qualitative assessment) (105). In the semi-quantitative assessment, the percentage of positively stained cells is usually expressed using an interval system (e.g. 1-10\%, 11-50\% and so on) and then categorized in groups from e.g. 1-3. The interval systems are defined for each investigated biomarker. In the qualitative assessment the staining intensity is commonly scored from 0 - 3 corresponding to negative, weak positive, moderate positive and strong positive staining. In this thesis the protein expressions were scored by three different investigators independently, blinded to patient data and tumor characteristics, treatment, and outcome. The investigators included one pathologist that confirmed tumor content prior to scoring and two additional researchers (clinicians). In a separate session the scoring results were compared by the investigators and a definitive consensus score was determined by mutual agreement. 


\subsubsection{Papers I and II}

For survivin, WRAP53 $\beta$, and p53 the percentage of positively stained cells was scored as $0 \%$ $=0,<10 \%=1,10-50 \%=2$ or $>50 \%=3$; the staining intensity as $0=$ none, $1=$ weak, $2=$ moderate or 3 = strong. For WRAP53 $\beta$ the subcellular localization was scored as nuclear if the staining pattern was predominantly nuclear or equal between nucleus and cytoplasm; and nonnuclear, if there was no staining at all or cytoplasmic staining only. For EGFR membranestaining was evaluated using the HercepTestTM scoring system (DakoCytomation), which takes into consideration the percentage of positively stained cells and intensity (scores ranging from $0-3$, negative to strongly positive). Pictures of IHC staining for survivin, p53, EGFR are shown in Figure 2, paper I and for WRAP53 $\beta$ in Figure 1, paper II. For p16, all slides were scored by a pathologist for intensity of staining as follows: 0 (none), 1 (weak), 2 (moderate) or 3 (strong). Scores of 2 or 3 were considered positive when more than $70 \%$ of the target cells were stained diffusely in both the nucleus and cytoplasm.

\subsubsection{Paper III}

The scoring method for WRAP53 $\beta$ and survivin used in paper I and II were also used in paper III but with slight adjustments. For staining intensity the scores 2 and 3 were considered as positive, whereas 0 and 1 were considered as negative.

The scoring method of survivin was changed in order to be able to create an immunoreactive score (IRS) as applied by Engels et al (68). The percentage of positive cells was categorized in four groups instead of three $[0 \%=0,1-10 \%=1,11-50 \%=2,51-80 \%=3$ and $>80 \%=4]$ and scoring was performed for nuclear and cytoplasmic staining independently.

For the determination of the predominant subcellular localization the difference in staining intensity between nucleus and cytoplasm was used in WRAP53 $\beta$, scored in the same way as in paper II. The predominant localization of survivin was categorized into predominantly nuclear, equal nuclear and cytoplasmic or predominantly cytoplasmic. 


\subsection{Western Blot}

Western blot is a semi-quantitative method to separate and identify a specific protein in a mixture of proteins extracted from a cell. Separation is based on the protein's molecular weight and performed by gel electrophoresis, exploiting the fact that proteins of different sizes move with different speeds, and hence distances, through a polyacrylamide gel. The separated proteins are thereafter transferred to a nitrocellulose membrane which is incubated with a primary antibody for detection of the specific protein. For visualization, a secondary antibody labelled with a horseradish peroxidase (HRP) and a chemiluminescent substrate are added. This reaction creates a light-signal that corresponds to the position and amount of the specific protein in the sample (the stronger the signal, the higher the amount of protein). This signal is then recorded using a digital camera. Equal loading is verified by reprobing the membranes with a HRP-conjugated anti-actin antibody.

\subsection{Genotyping by PCR-restriction fragment length polymorphism}

\section{(RFLP)}

PCR-RFLP is a technique used to find variations in homologous DNA sequences. We used it to identify specific SNPs in DNA from the tumor biopsies. DNA-fragments containing the SNPs of interest were amplified by PCR. Restriction enzymes were then used to cut the DNA at the restriction enzyme recognition sites, resulting in restriction fragments of various lengths (=restriction digest). By gel electrophoresis the fragments were separated according to their lengths. Visualization was achieved by staining with ethidium bromide. The resulting various staining patterns are characteristic to specific SNPs.

\subsection{Gene silencing by siRNA transfection}

Small interference RNAs (siRNA, also known as silencing RNA) are short double-stranded RNAs that are used for silencing a particular target gene. After transfection into the cell, siRNAs 
become part of a RISC-complex (RNA-induced silencing complex) and are unwound into two single stranded RNAs. One single strand RNA is contained in the RISC complex. It is complementary to the target mRNA and thus recognizes it, binds it and induces its degradation and thereby non-translation of the target gene. Transfection of cell lines with siRNA was used in papers I, II and IV to downregulate the expression of survivin, WRAP53 $\beta$, and HIF-1 $\alpha$ in order to investigate the role of these proteins in intrinsic treatment sensitivity and/ or proliferation. Knockdown of $70-80 \%$ was achieved in all experiments and verified at mRNA level by quantitative real-time PCR (RT-qPCR), and at protein level by Western Blot.

\subsection{Reverse Transcriptase- quantitative Polymerase Chain Reaction (RT- qPCR)}

RT-qPCR combines two methods for detecting gene expression in a cell. Reverse transcriptase generates complementary DNA (cDNA) from extracted RNA, reflecting RNA expression of a particular gene in a sample. The cDNA is thereafter amplified by real-time PCR (=qPCR) in an automated system where the amplification of the cDNA is quantitatively measured with the help of a fluorescent dye in real time (in contrast to traditional PCR, where the amplified DNA is first measured at the end of the process). In this thesis we used a 7500 Fast Real Time PCR system for RT-qPCR in order to verify downregulation of specific mRNAs quantitatively. The comparative $\mathrm{C}_{\mathrm{t}}$ method was applied to determine expression levels relative to untreated controls. Amplification of two housekeeping genes, GAPDH and $\beta$-actin, were used as internal standards.

\subsection{Intrinsic treatment sensitivity}

Intrinsic treatment sensitivity in cell lines is determined by the fraction of surviving cells/colonies after a given treatment compared to the amount of cells/colonies in an untreated control group. Intrinsic radiosensitivity (IR) was assessed in papers I, II and IV. Cells were 
irradiated with $4 \mathrm{MeV}$ photons generated by a linear accelerator (Clinac 4/100, Varian, Palo Alto, CA, USA), delivering a dose-rate of $2.0 \mathrm{~Gy} /$ minute $(2,4,6,8$, and 10 Gy). Intrinsic sensitivity for cisplatin (ICS), cetuximab (ICmabS), and dasatinib was assessed in paper IV. Increasing doses of cetuximab $\left(15,30\right.$, and $60 \mathrm{nM}$; Erbitux ${ }^{\circledR}$, Merck KGaA, Darmstadt, Germany), cisplatin $(0.1,0.25,0.5 \mu \mathrm{g} / \mathrm{mL})$ or dasatinib $\left(5,10,20 \mathrm{nM}\right.$; Sprycel $^{\circledR}$, Bristol-Myers Squibb, New York, USA) were added to the cell cultures and incubated 9 days before evaluation. We used two different methods for the assessment of intrinsic treatment sensitivity: crystal violet assay (papers I, II and IV) and clonogenic assay (papers I and II). All experiments were carried out three times, independently from each other and the means and standard variations were calculated.

\subsubsection{Crystal violet assay}

The crystal violet assay is a quantative method where the amount of adherent cells is quantified. Cells were seeded into 12-well plates (Corning, Corning, NY, USA) with varying density (1000-3000 cells $\left./ \mathrm{cm}^{2}\right)$ according to the plating efficiency of each cell line. In papers I and II the cells were incubated in $37^{\circ} \mathrm{C}$ for 48 hours to allow for cell adhesion to the plate surface and then irradiated with 8 or 10 Gy. After another three days, attached cells were fixated with $4 \%$ paraformaledhyd for 20 minutes, followed by staining with crystal violet $(0.04 \%$ in $1 \%$ ethanol) for 20 minutes at room temperature. After solubilization in 1\% SDS (sodium dodecyl sulphate) the optical density (OD) at $550 \mathrm{~nm}$ was measured in a Victor plate reader (EG \& G Wallac, Upplands Väsby, Sweden). To determine the intrinsic sensitivity the average $\mathrm{OD}_{550}$ for the untreated control was set to $100 \%$. Subsequently, the percentage of the surviving cells after treatment was determined by comparing the average $\mathrm{OD}_{550}$ of the treated cells with the $\mathrm{OD}_{550}$ values of the untreated control. In paper IV, 24 hours after seeding the cell lines in 12-well plates, half of the cultures were moved to hypoxic conditions and cultured in $1 \% \mathrm{O}_{2}$. The rest of the cultures were cultured under standard conditions $\left(20 \% \mathrm{O}_{2}\right)$. After another $24 \mathrm{~h}$, cetuximab, 
cisplatin, or dasatinib was added or cells were irradiated with 2,4 , or 6 Gy. The crystal violet assay was performed 9 days after treatment as described above.

\subsubsection{Clonogenic assay}

The clonogenic assay (also called colony forming assay) is based on the ability of a single cell to proliferate indefinitely and grow into a large colony (consisting of $>32$ cells). It assesses the capacity of cells to reproduce and form colonies (or clones, therefore the name „clonogenic“). By comparing the colony-forming ability of treated cells with untreated controls intrinsic treatment sensitivity can be determined. The clonogenic assay is the method of choice to determine the effect of irradiation of cells in vitro, but can also be used for chemical compounds. We used this method in papers I and II to confirm our crystal violet assay results. Eight days after irradiation of the cells $(0,2,4$, or 6 Gy) they were fixed in $4 \%$ paraformaldehyde and stained with crystal violet. Colonies containing at least 32 cells each were counted on 6 separate plates for each dose. Surviving fraction was determined based on the plating efficiency of nonirradiated control cells.

\subsection{Statistics}

For survival analysis the Kaplan-Meier method with the endpoints overall survival (OS), disease-free survival (DFS), relapse-free survival (RFS), and disease-specific survival (DSS) was used. Differences between the groups were determined by Log-rank (Mantel-Cox) test. Binary logistic regression was used in papers I and II to determine the association between protein expression in the tumor tissues and treatment response. For analysis of tumor cell lines one-way Anova, followed by Bonferroni post hoc tests were used. P-values $\leq 0.05$ were considered statistically significant in all statistical tests used in this thesis. IBM SPSS Statistics version 19.0 was used in paper I, version 21.0 in papers II and IV, and version 22.0 in paper III. 



\section{RESULTS}

\subsection{Results paper I}

The aim of this study was to examine a series of markers in tumor biopsies obtained from HNSCC patients that were treated with radiotherapy, and investigate possible associations between these markers and outcome of radiotherapy. As mentioned in section Material and Methods, 40 patients that received radiotherapy were included, grouped into Non-responders $(n=20)$ and Responders $(n=20)$ according to treatment outcome. Patient characteristics are listed in Figure 1 in paper I. Smoking habits (not shown in Figure 1) were as follows: 9 non-smokers (6 Non-responders/3 Responders), 18 smokers ( $8 \mathrm{NR} / 10 \mathrm{R}$ ), 5 former smokers (3 NR/2R), and 8 with unknown smoking history (3 NR/ 5 R).

\subsubsection{Survivin}

IHC scoring results for staining intensity of survivin are shown in Figure 7, depicting the distribution in the Non-responder (NR) and the Responder (R) groups.

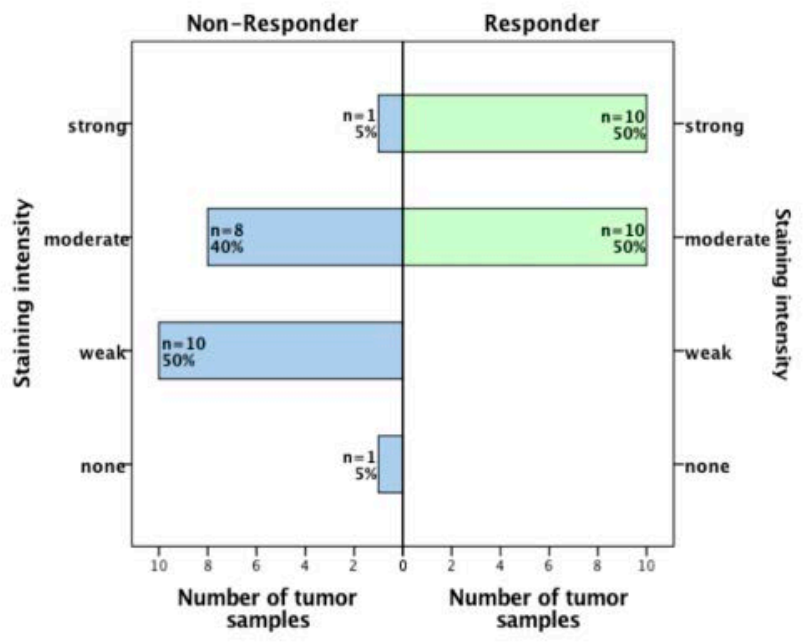

Figure 7. Survivin expression according to staining intensity in Non-Responders and Responders. 


\section{RESULTS}

The scoring results of the percentage of positively stained cells was homogenous throughout the study material: 39 of the samples expressed survivin in $>50 \%$ of the tumor cells, one sample showed no staining at all. Statistically, strong staining intensity of survivin was associated with positive response to radiotherapy (binary logistic regression: $\mathrm{p}=0.003$ ). Moreover, strong and moderate staining intensity were associated with improved overall survival compared to weak staining intensity (Kaplan-Meier: $\mathrm{p}<0.001$ and $\mathrm{p}=0.009$ respectively, Figure 3, paper I). To evaluate the impact of survivin on radiotherapy response we downregulated survivin by siRNA transfection in two cell lines (LK0412 and LK0949) and studied the effect on radiotherapy response. In both cell lines, significantly increased radioresistance was observed after downregulation of survivin [determined by crystal violet and confirmed by clonogenic assay (shown in Figure 4 in paper I)]. Cells with downregulated survivin also showed attenuated proliferation compared to the negative control.

\subsubsection{P53, EGFR, and p16}

Percentage of positively stained cells and staining intensity of p53 are shown in Figure 8. No association between p53 expression and radiotherapy response was found. However, in KaplanMeier analysis improved overall survival was associated with higher percentage of positively stained cells ( $p=0.015$, Figure 3 , paper I). There was no association between staining intensity and overall survival. 
$A$

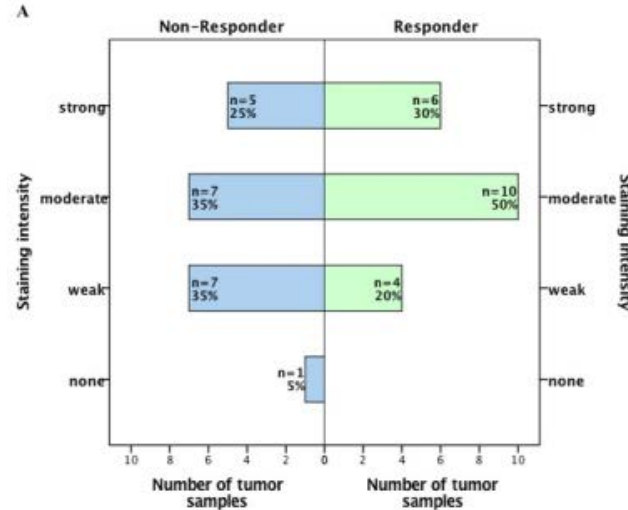

B

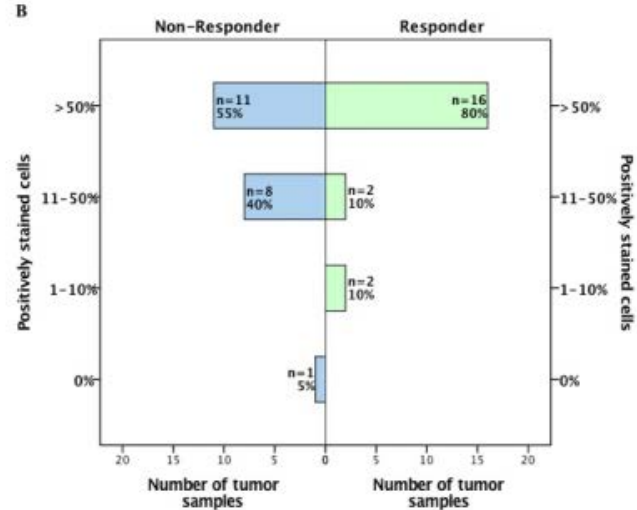

Figure 8. The expression of p53 according to staining intensity (A) and positively stained cells $(B)$ in Non-Responders and Responders.

As described in the Material and Methods section another scoring system was used for EGFR, combining the quantitative and qualitative expression of EGFR in one score. The scoring results are shown in Figure 9. No statistically significant associations were found between EGFR score and radiotherapy response or overall survival. Positivity for p16 was found in only two samples (base of tongue and hypopharynx), both in the Responder group.

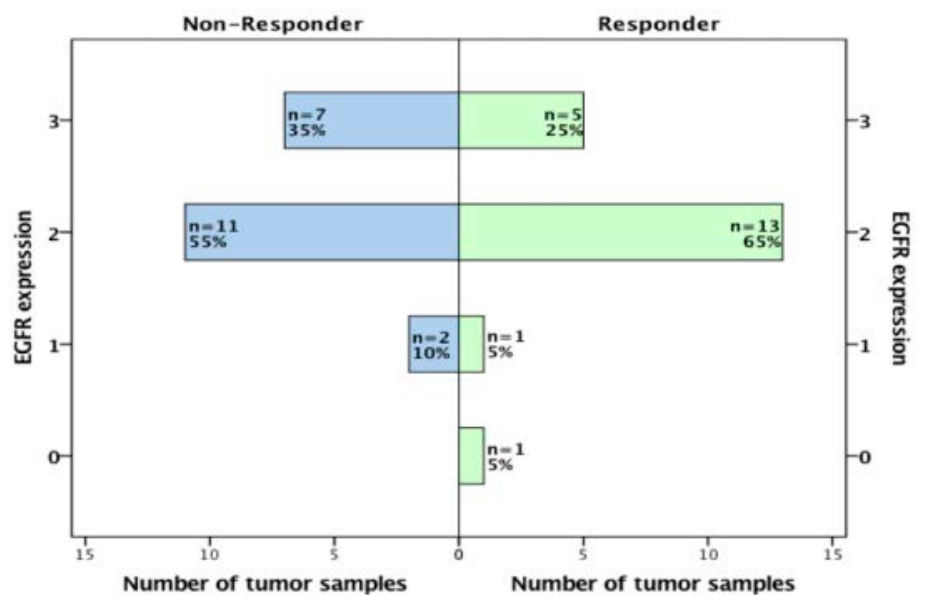

Figure 9. EGFR expression according to EGFR score in Non-Responders and Responders. 


\section{RESULTS}

\subsubsection{SNPs}

All tumor samples were tested for the existence of specific SNPs as described in section 1.5.2.7. The number of tumor samples with a variant allele is listed in Table 1, paper I. No significant associations were found between the existence of a SNP and radiotherapy response. Overall survival was significantly worse for patients with the SNP XPD Lys751Gln compared to those with the wildtype ( $\mathrm{p}=0.048$, Kaplan-Meier, Figure 3, paper I). In contrary, patients with the SNP FGFR4 Gln388Arg had a significantly longer overall survival compared to patients with wildtype ( $p=0.010$, Kaplan-Meier, Figure 3, paper I). For the other SNPs tested no significant associations were found with overall survival.

\subsection{Results paper II}

In this paper, the same study material as in paper I was used to investigate the expression of WRAP53 $\beta$ in tumor biopsies. Furthermore, we tested 39 of the tumor samples for two SNPs in the WRAP gene (rs2287499 and rs2287498) and analyzed their possible association with radiotherapy response and survival. 


\subsubsection{WRAP53ß}

The IHC scoring results of WRAP53 $\beta$ are summarized in Figure 10.
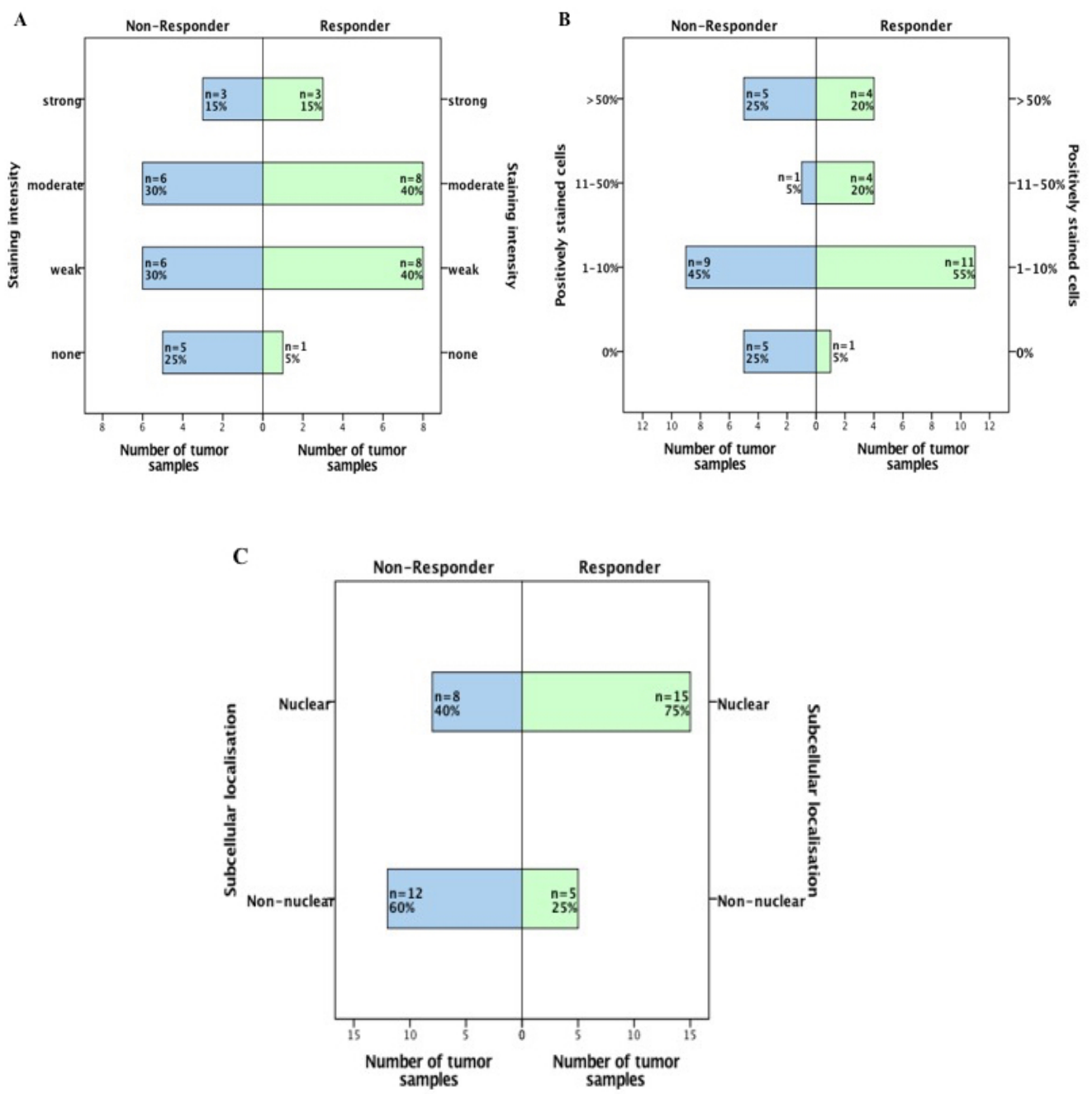

Figure 10. The expression of WRAP53 $\beta$ according to staining intensity (A), positively stained cells (B), and subcellular localization (C) in Non-Responders and Responders. 


\section{RESULTS}

The subcellular localization was the only variable that differed significantly between the groups $(\mathrm{p}=0.025$, Chi-square-test) and showed significant associations with radiotherapy response ( $\mathrm{p}$ $=0.029$, binary logistic regression) and overall survival $(\mathrm{p}=0.014$, Kaplan-Meier, Figure 2, paper II), in which patients with nuclear WRAP53 $\beta$ showed a favorable outcome. We also examined if a combination of nuclear WRAP53 $\beta$ and survivin would enhance the significant difference in treatment outcome and overall survival. The combination of nuclear WRAP53 $\beta$ and strong survivin was associated with the most favorable overall survival compared to other combinations (Kaplan-Meier: $\mathrm{p}=0.001$, compared to non-nuclear WRAP53 $\beta$ with various survivin expression, Figure 4, paper II). Downregulation of WRAP53 $\beta$ in the two cell lines [LK0412 (80\%) and LK0949(70\%)] was achieved using a WRAP53ß-specific siRNA oligonucleotide. Upon downregulation of WRAP $53 \beta$, the proliferation rate decreased in one of the cell lines $(\mathrm{LK} 0412 ; \mathrm{p}=0.01)$ and resistance to radiation increased compared with siRNAnegative controls (crystal violet assay: $\mathrm{p}<0.001$ for both cell lines, Figure 3, paper II). Clonogenic assay confirmed an increased resistance to radiotherapy after silencing of WRAP53 $\beta$ compared to the negative controls (Figure 3, paper II). The existence of SNPs was demonstrated in 7 tumor samples, in which both investigated SNPs were found consistently together. Frequency of genotypes and the distributions between NR and R are presented in Figure 11. 


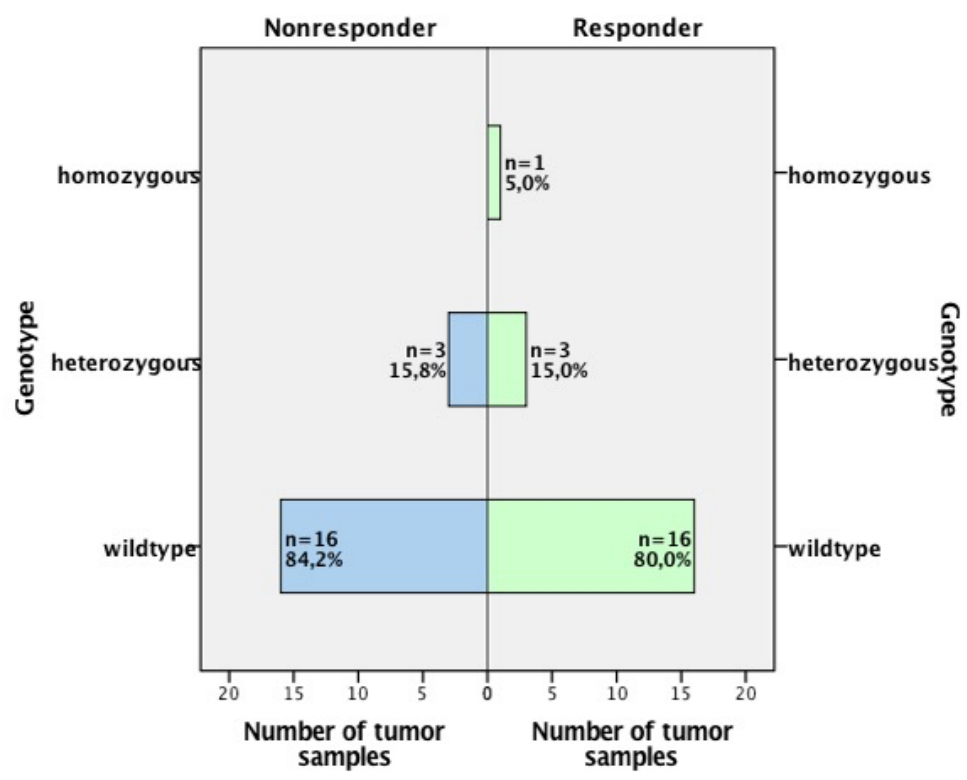

Figure 11. The frequency of genotypes for SNPs rs2287498 and rs2287499 in Non-Responders and Responders.

Statistically, there were no significant associations between the SNPs and radiotherapy response or SNPs and overall survival, nor an association between the SNPs and the subcellular localization of WRAP53 $\beta$.

\subsection{Results paper III}

The aim of paper III was to further investigate survivin, WRAP53 $\beta$, and p16 expression in a larger and more homogenous cohort. One subgroup within HNSCC where predictive markers of radiotherapy response would be extremely helpful is glottic laryngeal SCC classified as T2N0-T3N0. Treatment results in this patient group are suboptimal (106) and one explanation might be the use of organ preservation treatment (RT or CRT) as an alternative to radical surgery (often total laryngectomy). Thus, we gathered 149 tumor samples with glottic laryngeal SCC classified as T2N0-T3N0, primarily oncological treated. 


\section{RESULTS}

\subsubsection{Survivin}

148 samples were successfully stained for survivin. One sample was lost due to staining failure. Kaplan-Meier- analysis was performed for each factor itself as well as for immuno-reactive scores determined according to Engels et al (68). Statistically, no significant correlations were found between survival (OS, RSS, DFS, DSS) and survivin expression when analyzing the whole study material. In the subgroup of tumors with predominantly nuclear staining, KaplanMeier-analysis showed a similar survival pattern as in paper I with a higher survival rate in patients with strong survivin staining compared to those with weaker staining ( $58 \%$ vs $33 \%$ ). However, results were not significant ( $\mathrm{p}=0.091$, Figure 4, paper III).

\subsubsection{WRAP53ß}

All 149 samples were successfully stained for WRAP53 $\beta$. The tumor samples showed a highly heterogeneous staining pattern within the samples which entailed difficulties in the scoring of the percentage of positive cells. Consequently this variable was excluded from further investigation. Staining intensity and subcellular localization were used to determine the subgroups: nuclear positive samples $(n=75,50 \%)$, cytoplasm positive samples $(n=15,10 \%)$, and nuclear negative and cytoplasm negative, the latter being combined to negative subgroup $(\mathrm{n}=59,40 \%)$. Kaplan-Meier-analysis revealed a significant difference in 5-year- DFS between patients with positive nuclear staining compared to patients with positive cytoplasmic staining with a worse outcome for the latter $(p=0.022$, survival rate: $54 \%$ vs $27 \%$, Figure 3 , paper III). Moreover, even though the results were not significant, survival rates for patients in the positive cytoplasmic subgroup appeared worse compared to patients whose tumors were classified as negative for WRAP53 $\beta$ staining ( $55 \%$ vs $27 \%, \mathrm{p}=0.072$, Figure 3 , paper III).

\subsection{3 p16}

Eleven tumor samples were classified as p16-positive. There were no significant differences in survival endpoints between p16-negative and p16-positive patients. The exclusion of p1646 
positive samples did not impact the significance of the above mentioned results. However, it is noteworthy that patients younger than 60 years showed a higher frequency of p16-positivity compared to those $\geq 60$ years $(\mathrm{p}=0.017)$. Within this younger age group the following observations were made: non-smokers were more commonly p16-positive $(p=0.022)$ and $p 16$ positive patients developed no recurrences and had a significantly longer DFS compared to p16negative patients $(\mathrm{p}=0.041$ and $\mathrm{p}=0.021$, respectively).

\subsubsection{Additional results}

Regarding clinical data, we observed that $\mathrm{T} 3 \mathrm{~N} 0$ patients primarily treated with chemoradiotherapy had an improved outcome compared to patients treated with radiotherapy only, with regard to 5-year survival endpoints (OS: $p=0.001$; DSS: $p=0.018$; DFS: $p=0.001$; RFS: $p=0.039$, Table II, paper III $)$ as well as recurrences $(p<0.001)$.

\subsection{Results paper IV}

The aim of paper IV was to investigate the impact of hypoxia and the role of HIF-1 $\alpha$ regarding treatment response, EMT profile, and expression of CSC markers in HNSCC.

\subsubsection{Impact of hypoxia on treatment response}

Five cell lines, cultured in normoxic and hypoxic conditions, were treated with cetuximab, cisplatin, dasatinib, and radiation, and differences in treatment responses were determined. Changes in treatment sensitivity were observed mainly in cell lines with a primarily epithelial phenotype (LK0412, UT-SCC-2, UT-SCC-14) as compared to no/minor changes in cell lines with a mesenchymal phenotype (LK0827, LK0923). The most noteworthy observation was that LK0412 cells became distinctly more sensitive to cetuximab in hypoxic conditions which was in contrast to our expectations and to the results from the other cell lines. The results are shown in Figure 1A, in paper IV. 


\subsubsection{The impact of hypoxia on EMT profile and cancer stem cell markers}

As expected, cells cultured in hypoxic conditions went through morphological changes from an epithelial phenotype to a more mesenchymal phenotype. In all analyzed cell lines, cells cultured in hypoxic conditions exhibited looser contact with neighboring cells when compared with cells cultured in normoxia (Figure 12).

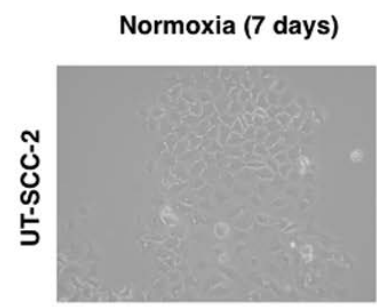

Hypoxia (7 days)
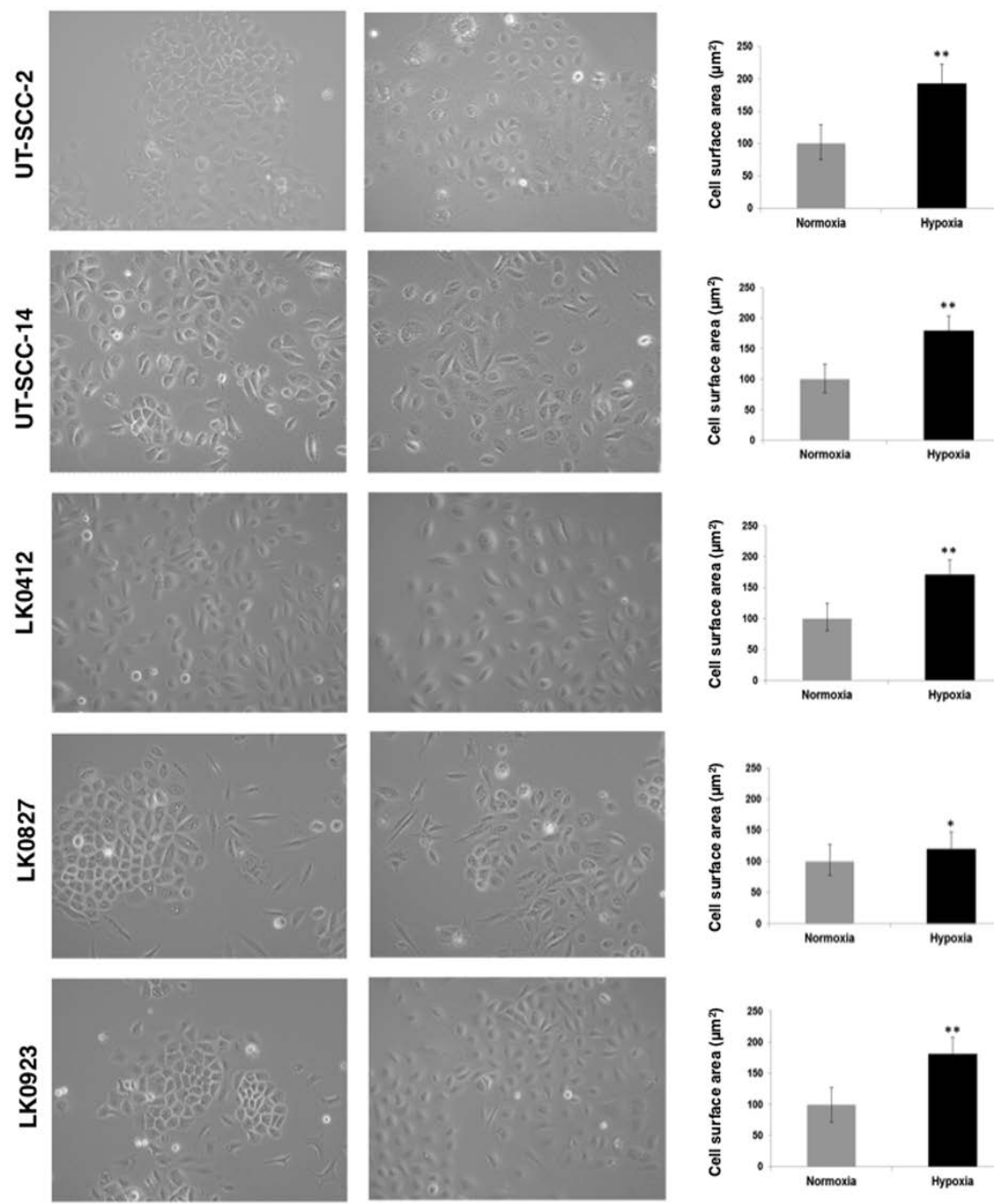

Figure 12. Morphological changes in EMT-profile under hypoxic conditions. 
Changes in EMT profile were determined by differences in mRNA expression of epithelial and mesenchymal markers, shown in Figure 2A, paper IV. The transformation from epithelial to mesenchymal phenotype was marked by significant downregulation of E-cadherin (UT-SCC-2 and UT-SCC-14) and significant upregulation of N-cadherin (LK0412, UT-SCC-2 and UTSCC-14) as well as fibronectin and vimentin (for LK0412 and UT-SCC-2, UT-SCC-14 showed a non-significant increase). Moreover, a higher level of the stem cell transcription factors Nanog and Sox1 were shown in cells cultured in hypoxic conditions (Figure 2A and 2B, paper IV).

\subsubsection{The impact of HIF-1 $\alpha$ on treatment response, EMT profile, and CSC markers}

For further analysis of the importance of HIF-1 $\alpha$ the two cell lines with the most pronounced changes in treatment response in hypoxic conditions were chosen (LK0412 and UT-SCC-14). After downregulation of HIF-1 $\alpha$ by siRNA transfection, normoxic and hypoxic cells were treated with cetuximab and cisplatin. UT-SCC-14 showed only minor changes in treatment response upon downregulation of HIF-1 $\alpha$. LK0412 cells with depleted HIF-1 $\alpha$ still showed a decreased survival rate upon cetuximab treatment in hypoxia compared to normoxia but to a significantly lower extent than siRNA-negative treated cells. (Figure $3 \mathrm{C}$ and D in paper IV). Downregulation of HIF-1 $\alpha$ reversed the above described changes of EMT markers in both cell lines, as reflected by the high expression level of E-cadherin in hypoxia and downregulation of N-Cadherin, vimentin, and fibronectin (Figure 4A in paper IV). In LK0412, Nanog was expressed at a significantly lower level after silencing of HIF-1 $\alpha$. Otherwise no significant changes in CSC markers were shown. 


\subsubsection{The impact of hypoxia on EGFR signaling molecules and cetuximab treatment}

In order to investigate the impact of hypoxia and HIF-1 $\alpha$ on cetuximab-treatment response, the effects of hypoxia, HIF-1 $\alpha$ depletion and cetuximab treatment on EGFR downstream signalling were analyzed by Western blot (results shown in Figure 5, paper IV). The inhibition of pEGFR by cetuximab in LK0412 cells was significantly greater in hypoxia than in normoxia which is in concordance with the observation that LK0412 cells became more sensitive to cetuximab in hypoxia. The downregulation of HIF-1 $\alpha$ with or without cetuximab treatment did neither attenuate or amplify this effect. In contrast, no changes of pEGFR expression were found for UT-SCC-14 cells. In normoxia, cetuximab treatment led to a reduced activation of pAkt in both cell lines. This effect was not demonstrated in hypoxia but could be induced by HIF-1 $\alpha$ depletion and/ or the combination of HIF-1 $\alpha$ depletion with cetuximab treatment, in which the latter was more effective. 


\section{DISCUSSION}

Today, there are no established, reliable predictive markers for radiotherapy response in HNSCC patients, despite tremendous research efforts. The identification of predictive markers would refine the decision-making process and improve patient outcome by stratifying the patients to an optimal treatment. The studies in paper I, II, and III were initiated to investigate potential biomarkers of radiotherapy response using IHC. Two benefits of using IHC are that the method is reasonably inexpensive and can be easily performed in conjunction with routine clinical diagnostics.

\subsection{The impact of survivin on treatment response and survival in HNSCC in general and in glottic ISCC in particular (Papers I and III)}

The most interesting finding in paper I was the differential expression of survivin between Nonresponders and Responders to radiotherapy. Strong survivin expression was significantly associated with improved radiotherapy response and longer overall survival. These results were in contrast to other studies that reported a poor prognosis in tumors overexpressing survivin $(64,107)$. In those studies, the expression of survivin was determined by the percentage of positively stained cells only, without consideration of the staining intensity. Moreover, only survival was assessed but not association with treatments. Our results, however, were based on staining intensity only, and we specifically assessed survivin expression in two groups with different treatment responses. Our in vitro data showing increased radioresistance in HNSCC cell lines upon survivin-depletion, suggest that survivin may itself play a role in influencing radiosensitivity. We also observed an attenuated proliferation of tumor cells upon silencing survivin, suggesting that survivin's effects on radiosensitivity may be mediated by its effects on proliferation rate. This might explain the seemingly conflicting observations of survivin being linked to a more aggressive tumor growth and yet improving the response to radiotherapy. 


\section{DISCUSSION}

Decreased proliferation and increased apoptosis upon knock-down of survivin was also shown in cell lines derived from lung cancer and esophageal SCC $(108,109)$. In agreement with our results, other studies have shown that patients with oral SCC demonstrating high survivin expression have a favorable response to radiotherapy $(67,68)$. Similar results were shown for patients with breast cancer (110) and colon cancer (111). Those studies revealed a better prognosis and overall survival for patients with nuclear survivin expression.

Though our results for survivin were significant, the small sample size and the heterogeneity of tumor sites are weaknesses in the study, and the results should be interpreted cautiously. Further evaluation of survivin expression was performed in a multicenter study including only patients with T2N0-T3N0 glottic laryngeal SCC (paper III). However, in this study we found no significant association between survivin expression and survival. One possible explanation is variation in the IHC staining procedure in paper I and III, possibly influencing detection of survivin in relation to the subcellular location, as more frequent cytoplasmic survivin staining was noted in the tumor material used for paper III. Interestingly, when we investigated the subgroup of patients with predominant nuclear staining we found a similar survival pattern as in paper I, with a trend towards improved DFS with strong nuclear staining intensity compared to weak nuclear staining intensity. Statistically, this association was not significant and should be interpreted carefully. Another explanation might be differences in treatment modalities (paper I included surgical treatment while paper III only included primary oncological treatment). Moreover, the selection of patients in paper I (NR and R) might have yielded a cohort of patients with extreme outcomes, while the larger study cohort of paper III consisted of patients with more heterogeneous outcomes. Finally, the selection of one specific tumor site (paper III) may contribute to the differing results. The role of survivin in laryngeal SCC might differ from its role in HNSCC from other subsites. There are studies on survivin in laryngeal SCC that have linked survivin expression to an unfavorable outcome $(66,112)$, and yet others 
that, like ours, showed no connection between radiotherapy response and survivin (113). Divergent scoring methods, as well as differences in tumor classification (TNM), and treatment approaches may explain the contradictory results. In conclusion, while our results in paper I suggest a role of survivin in radiotherapy response, no associations between survivin and outcome could be shown in T2N0-T3N0 glottic laryngeal SCC. Survivin's role in other subsites included in paper I might be more relevant than in laryngeal cancer.

\subsection{The impact of WRAP53 $\beta$ on treatment response and survival in}

\section{HNSCC in general and in glottic ISCC in particular (Papers II and III)}

WRAP53 $\beta$ has emerged as a promising factor in cancer research and has been suggested as a potential prognostic marker as well as a candidate for targeted anti-cancer therapy (75). Study II in this thesis highlighted the role of nuclear expression of WRAP53 $\beta$ in radiotherapy response. Nuclear WRAP53 $\beta$ was more common in Responders to radiotherapy and linked to improved treatment response as well as longer overall survival. These findings were supported by in vitro data from two HNSCC cell lines which developed resistance to radiation after knockdown of WRAP53 $\beta$. In a study on patients with metastatic rectal cancer, expression of WRAP53 $\beta$ in metastases correlated to better outcome in patients treated preoperatively with radiotherapy (76), an observation that was not made in non-irradiated patients. These results support our findings that WRAP53 $\beta$ is of importance for response to radiotherapy. On the contrary, Mahmoudi et al showed that high WRAP53 $\beta$ protein level correlated to poorer outcome and low intrinsic radiosensitivity in HNSCC cell lines, and knock-down of WRAP53 $\beta$ resulted in increased apoptosis and improved radiosensitivity (75). Our experiments showed lower cell proliferation after depletion of WRAP53 $\beta$ in one of the cell lines. Since no significant changes in cell proliferation were observed in the second cell line, it seems unlikely that decreased proliferation alone can explain the increased radioresistance in WRAP53 $\beta$-deficient cells. Another interesting aspect is the involvement of WRAP53 $\beta$ in telomere elongation. 


\section{DISCUSSION}

Telomeres exceeding a certain length correlate to higher radiosensitivity (114). Moreover, telomere dysfunction has been linked to radioresistance in oral cancer cells (115). Depletion of WRAP53 $\beta$ may lead to impaired telomere elongation and thereby promote radioresistance. These findings support that WRAP53 $\beta$ is linked to response to radiotherapy and might have a predictive value.

The combination of nuclear WRAP53 $\beta$ and strong survivin staining intensity was also associated with longer overall survival, however, the combination of the two factors was not significantly better than looking at survivin expression alone (paper II). While logistic regression failed to show an association with radiotherapy response, it is noteworthy that 15 samples in the Responder group expressed the combination of nuclear WRAP53 $\beta$ and strong survivin versus only three in the Non-responder group. The majority of Non-responders showed non-nuclear WRAP53 $\beta$ staining and variable survivin expression. A larger study is likely needed in order to better evaluate any additional predictive information provided by the combination of these factors.

Further evaluation of WRAP53 $\beta$ was performed in the cohort of patients with glottic laryngeal SCC (paper III). In this cohort, positive nuclear WRAP53 $\beta$ expression was associated with longer disease-free survival, compared to patients with positive cytoplasmic WRAP53 $\beta$. Interestingly, there was no significant difference in survival between patients with positive nuclear staining compared to those classified as negative, while patients with positive cytoplasmic staining had a shorter disease-free survival compared to both other groups. This made us question whether the accumulation of WRAP53 $\beta$ in the cytoplasm may be the relevant prognostic factor in this patient cohort, instead of nuclear WRAP53 $\beta$. In agreement with our findings, Kaplan-Meier-curves revealed worse survival for breast cancer patients with negative nuclear/ positive cytoplasmic expression of WRAP53 $\beta$ (81). The biological relevance of the subcellular localization of WRAP53 $\beta$ still has to be elucidated. Increased accumulation of 
WRAP53 $\beta$ in the cytoplasm may reflect disrupted intracellular passage into the nucleus, consequently hindering nuclear functions of WRAP53 $\beta$. In epithelial ovarian cancer, low nuclear WRAP53 $\beta$ correlated to poor prognosis. After downregulation of WRAP53 $\beta$, impaired DNA repair was observed and a connection between genomic instability and carcinogenesis with low expression of nuclear WRAP53 $\beta$ was suggested (116). The same consequences may occur if WRAP53 $\beta$ is trapped in the cytoplasm. Most known functions of WRAP53 $\beta$ are carried out in the nucleus and little is known about cytoplasmic WRAP53 $\beta$ functions.

In conclusion, WRAP53 $\beta$ shows potential as a predictive marker for radiotherapy response, and the most important factor seems to be its intracellular localization. More specifically, it appears that accumulation of WRAP53 $\beta$ in the cytoplasm may be a negative prognostic factor in HNSCC. Further in-depth analysis is needed in order to elucidate the subcellular functions of WRAP53 $\beta$ and the significance of its subcellular localization in relation to treatment outcome.

\subsection{The role of p16 in papers I - III}

The significance of HPV-status in oropharyngeal cancer has led to changes in the TNMclassification that is used by clinicians as help in treatment decision-making. In the American Joint Committee on Cancer Staging Manual, oropharyngeal cancer will now be classified according to high-risk HPV-associated cancer and cancer of other cause (117). It is widely recognized that $\mathrm{HPV}^{+}$oropharyngeal cancer has a favorable prognosis and responds better to radiotherapy. $\mathrm{p} 16^{\mathrm{INK} 4 \mathrm{a}}$ is used as a surrogate marker for HPV in oropharyngeal cancer and is in itself a marker for improved treatment outcome (118). In paper I, only two samples were positive for p16 and both samples belonged to Responders to radiotherapy. Exclusion of these samples did not alter the other findings described in paper I. The probability that cancer in other subsites than the oropharynx is caused by high-risk HPV is at least 5-fold lower and presumably rare (119). Nevertheless, based on limited data, an estimated 7\% of laryngeal HNC might be attributed to HPV (119). Interestingly, in paper III, 7\% of the tumor samples were positive for 


\section{DISCUSSION}

p16. The significance of p16 in non-oropharyngeal HNSCC is disputed, but there are studies that have shown a prognostic value of p16 in other sites (120). In terms of prognosis, survival outcome did not differ between p16- positive and -negative samples in our study. Nonetheless, it is noteworthy that p16-positivity was more common in patients under 60 years, and was associated with non-smokers, absence of recurrence, and improved DFS. The former two observations have also been described in a study of Kalfert et al (121) and Baumann et al have described an association between p16-prevalence in laryngeal SCC and younger age (122). Taking these findings together, p16 might have a prognostic value in a distinct subgroup of patients with laryngeal SCC, although further investigations are needed.

\subsection{The impact of hypoxia on HNSCC cell lines}

Hypoxia, EMT, and CSC are independently acknowledged contributors to treatment resistance in squamous cell carcinomas. In the last years, it has also become clear that these processes are interconnected (123-126), although the exact mechanisms of this interaction are yet unknown. In paper IV our results show that hypoxia induces EMT in three primarily epithelial HNSCC cell lines and renders a majority of the cell lines more resistant to treatment with cetuximab, cisplatin and irradiation. Surprisingly, the LK0412 cell line, also primarily epithelial, became more sensitive to cetuximab-treatment when cultured in hypoxic conditions. In addition, HIF$1 \alpha$ depletion resulted in increased cetuximab-resistance in this cell line compared to hypoxic cells with retained HIF-1 $\alpha$. This suggests an involvement of HIF-1 $\alpha$ in sensitization of cells to cetuximab-treatment in this cell line. In agreement with our results, the study of Boeckx et al showed hypoxia-mediated sensitization to cetuximab and erlotinib in one HNSCC cell line each (127). However, the role of HIF-1 $\alpha$ in their observations was not tested. As HIF-1 $\alpha$ overexpression has been correlated with poor prognosis and outcome, the combination of drugs targeting HIF-1 $\alpha$ and cetuximab has been suggested in order to gain maximal therapeutic effect (88). Thus, it appears crucial to identify patients whose tumors become more sensitive in the 
presence of HIF-1 $\alpha$, as anti-HIF-1 $\alpha$ therapeutics may actually worsen the treatment response to cetuximab and potentially the patient's outcome. However, this reflection is based on findings in a single HNSCC cell line (one out of five analyzed) and further preclinical studies are need before conclusions can be made.

We further evaluated possible changes in EGFR downstream molecules driven by hypoxia. In our western blot analysis, we noted that the addition of cetuximab to the cells inactivated pEGFR to a greater extent in hypoxia than in normoxia in LK0412, an effect that was not observed in the UT-SCC-14 cell line (which became less sensitive in hypoxia). Since this effect in LK0412 was unchanged by knock-down of HIF-1 $\alpha$ it seems that there are other factors than HIF-1 $\alpha$ involved in this response. Interestingly, HIF-1 $\alpha$ depletion revoked the inactivation of Akt induced by cetuximab in hypoxia, suggesting that the suspected sensitizing effect of HIF$1 \alpha$ that we have observed might be related to this EGFR downstream molecule. Li et al showed that inhibition of PI3K by cetuximab is imperative for downregulation of HIF-1 $\alpha$ synthesis, and that this downregulation is required for maximum effect of cetuximab (88). It would be interesting to see how PI3K is affected in the LK0412 cell line, to see if an explanation for its sensitization to cetuximab can be found.

In one of our earlier studies, sensitivity to cetuximab-treatment in UT-SCC-14 cells was associated with cetuximab-mediated reduction of $\mathrm{pEGFR}$ in vivo and in vitro (128). In the current study, pEGFR expression was similar in both normoxic and hypoxic conditions in this cell line. No major reduction of pEGFR by cetuximab was noted and knock-down of HIF-1 $\alpha$ did not change the pEGFR expression. Nevertheless, UT-SCC-14 became less sensitive to cetuximab in hypoxia and this change was largely unaffected by HIF-1 $\alpha$ depletion, suggesting that there are other mechanisms involved in the decreased cetuximab response than HIF-1 $\alpha$. However, hypoxia reversed cetuximab-induced inactivation of pAkt, a result that seems to be HIF-1 $\alpha$ - dependent. Considering the PI3K/Akt pathway as pro-survival, this might explain the 


\section{DISCUSSION}

increased resistance in hypoxia. However, a similar pattern was found for LK0412 which becomes more sensitive to cetuximab in hypoxia, emphasizing our assumption that other mechanisms to hypoxia-related resistance to cetuximab have to be considered, e.g. tumorspecific mutations within the K-ras gene (88).

UT-SCC-2 showed high base levels of HIF-1 $\alpha$ and less distinct differences in cetuximabreponse between normoxic and hypoxic cells compared to the other epithelial cell lines. HIF$1 \alpha$ stabilization in normoxic cells has recently been described in prostate cancer, mediated by beta-arrestin 1 (ARRB1) (129). In this study, it is suggested that "pseudohypoxia" contributes to adaption of cancer cells leading to a growth advantage. This might also be the case in our cell line and further investigations on HIF-1 $\alpha$ stabilization and its impact on treatment response might be of interest. In the same cell line, cetuximab reduced HIF-1 $\alpha$ expression more distinctly as compared to the other epithelial cell lines in which only minor reduction of HIF-1 $\alpha$ could be observed. Luwor et al proposed that mutations within the PTEN gene render cancer cells more resistant to cetuximab-mediated reduction of the HIF-1 $\alpha$ level (130), which could also be of importance in our observations. Cell lines with primarily mesenchymal phenotype (LK0827 and LK0923) showed no effect of cetuximab on HIF-1 $\alpha$ expression and only a few significant differences in treatment response between normoxia and hypoxia were found in these cell lines. This suggests that in tumors with a more EMT phenotype, mechanisms other than hypoxia are responsible for treatment resistance. In contrast to this, we found that the primarily epithelial cell lines (LK0412, UT-SCC-2, and UT-SCC-14) that responded significantly differently to treatment in hypoxia, underwent hypoxia-induced EMT and expressed increased stem-like transcription factors in hypoxic conditions. These observations were only partially reversed by cetuximab or HIF-1 $\alpha$ siRNA. This suggests, that inhibition of HIF-1 $\alpha$ may not be sufficient to overcome hypoxia-induced EMT and stem-like phenotypes, and that factors other than HIF-1 $\alpha$ are of importance in hypoxia-induced changes towards a more malignant phenotype. Decreased 
sensitivity to treatment with cetuximab, cisplatin, and radiation in hypoxic UT-SCC-2 and UTSCC-14 cells has been attributed to gain of a mesenchymal phenotype. These findings are supported by a study of Holz et al (131) that also showed decreased radiosensitivity in HNSCC cells with a mesenchymal phenotype, and is in agreement with our previous findings that the mesenchymal marker FN1 is upregulated in radioresistant cells (50).

In conclusion, our study shows that hypoxia has more impact on epithelial phenotype cell lines than mesenchymal phenotype cell lines in regard to treatment response and phenotype changes. HIF-1 $\alpha$ depletion alone does not reverse hypoxia-induced effects, and it is possible that hypoxia and HIF-1 $\alpha$ play a role in sensitizing cancer cells to cetuximab treatment. Thus, targeting HIF$1 \alpha$ alone might not be the answer to improve response to anti-EGFR treatment in hypoxic tumors and other mechanisms and targets have to be taken into consideration. 



\section{CLINICAL RELEVANCE}

Identification of novel predictive biomarkers is imperative in order to maximize treatment effect and improve patient outcome. A tumor is a complex structure, with intricate intracellular signaling systems within the tumor cells themselves and with considerable cross-talk between tumor cells and cells in the microenvironment. To concentrate on only one factor will probably not be sufficient. More likely, tumor profiling using a combination of multiple characteristics will be needed. This may require an assortment of assessment methods to detect characteristics spanning from the gene to the protein level.

This thesis suggests that the proteins survivin and WRAP53 $\beta$ have potential as predictive biomarkers for radiotherapy response in HNSCC and might represent a puzzle piece in the overall picture. IHC-staining of these proteins would be relatively easy to implement in clinical routine, and potentially facilitate treatment-making decisions. The continued search for biomarkers may give rise to new targeted treatment strategies. Moreover, combinations of targeted drugs may prove to yield superior effects. Drugs targeting tumor hypoxia are under investigation and are suggested to optimize the effect of cetuximab. It will be important to further investigate if in some tumors hypoxia can increase sensitivity to cetuximab-treatment and, in that case, to find reliable markers to stratify patients to single treatment with cetuximab or to a combination of targeted drugs. 



\section{CONCLUSIONS}

In summary, the following conclusions can be made from the studies included in this thesis:

- The association of survivin with improved radiotherapy response and overall survival in paper I suggests that survivin may play a role in radiotherapy response.

- In glottic $1 \mathrm{SCC}$, however, there were no significant associations between survivin expression and survival, and thus, a predictive/ prognostic value of survivin in this HNSCC subtype could not be demonstrated. Together with the results of paper I, this may suggest that survivin's potential as a biomarker might vary between subsites of HNSCC.

- The subcellular localization of WRAP53 $\beta$ is associated with radiotherapy response and survival in HNSCC. WRAP53 $\beta$ appears to be a promising candidate biomarker in HNSCC in general and in glottic 1SCC in particular.

- The prevalence of $\mathrm{p} 16^{\mathrm{INK} 4 \mathrm{a}}$-positive glottic $1 \mathrm{SCC}$ tumor samples was higher in patients younger than 60 and associated with absence of recurrence and improved DFS, supporting $\mathrm{p} 16^{\mathrm{INK} 4 \mathrm{a}}$ as a possible prognostic marker in this subgroup of patients.

- Hypoxia influences intrinsic treatment response in epithelial phenotype HNSCC cell lines but affects the cell lines to different extents. The sensitizing effect of hypoxia on cetuximab-response as observed in one of these cell lines has to be evaluated further as it suggests that treatments targeting hypoxic areas may not lead to an improved outcome in all patients.

- Hypoxia and HIF-1 $\alpha$ induce EMT and an increase in expression of CSC markers in HNSCC cell lines. Depletion of HIF-1 $\alpha$ does not fully reverse these effects, 
CONCLUSIONS

indicating that targeting HIF-1 $\alpha$ might not be sufficient to improve treatment outcome. 


\section{FUTURE ASPECTS}

Determination of biomarker expression by IHC has its pitfalls, including both intra- and interobserver variability (105). A standardized interpretation method is warranted and digital tools such as image analysis may provide a means to more accurate and reproducible analyses. It would be interesting to develop a study where potential HNSCC biomarkers are analyzed using image analysis. In breast cancer, a recent study suggests that digital image analysis is superior to traditional microscopic assessment of the well-established biomarkers estrogen receptor, progesterone receptor, proliferation marker Ki-67 and HER2 (132).

Further investigation of survivin and WRAP53 $\beta$ in tumors of the oral cavity would be interesting, as a majority of the tumors examined in study I and II of this thesis were derived from this subsite. It would be interesting to see if these two proteins are more strongly associated with radiotherapy response and survival in this patient group.

As for the impact of hypoxia and HIF-1 $\alpha$, our preliminary results show no association between HIF-1 $\alpha$ expression (determined by IHC) and survival in glottic 1SCC treated with radiotherapy. It would be interesting to study other factors related to hypoxia, for instance HIF-2 $\alpha$, in relation to treatment outcome in HNSCC. 



\section{ACKNOWLEDGMENTS}

So many people have accompanied me during the time of my $\mathrm{PhD}$ and have contributed to this $\mathrm{PhD}$ thesis in many different ways. I would like to express my sincerest thanks to all of you.

Karin Roberg, who has been my main supervisor, and who has introduced me to the exciting field of research and has guided me from the very beginning. This thesis wouldn't have been possible without your advices, unlimited help, and great knowledge in the field. I am very grateful for everything you have done for me during the years. You have always had an open ear for all kinds of questions and worries, and have supported me even beyond research. The research lab has always been a place full of new knowledge, support and merriment thanks to your experience, openness and kindness.

Lovisa Farnebo, my co-supervisor and colleague. Your enthusiasm for research was contagious and really showed me how much fun research can be and how great it is to combine it with clinical life. I admire your ambition, your sincerity and your professionalism as much as your kindness and your joyfulness. You have the strength to make changes where they are needed! And of course, you are a great salsa dancer!

Stina Garvin, my co-supervisor. Thank you for all the patience you had when teaching me interpretation and scoring for immunohistochemistry, and for all the discussions and talks we had about research and life. You turn everything into fun! I really appreciate all your feedback and your thorough language corrections, but most of all, I am grateful for your friendship. Emilia Wiechec, co-author. I am so happy that you joined Karins group! It really is a great pleasure working with you. In the little time you have been at the lab I have learned so much from you and I really enjoyed all our talks about almost everything. You are the only person I know who has access to "free" pizza and I am so happy that you shared one with me. 


\section{ACKNOWLEDGMENTS}

Thanks to all fellow PhD students in the Öron-group. Anna Ansell-Schultz and Linnea Le

Fleur who have shown me how to perform the experiments. It always has been a delight to work with you and I am happy to call you my friends. My dear colleagues and friends Stella Melissaridou, Natasa Matic and Lisa Alexandersson who always manage to make me feel happy.

Karin Öllinger, Katarina Kågedal and all the other colleagues at the 9th floor at the department of pathology who have always been so kind and welcoming and made the working place a happy and joyful one. To Ann-Charlotte Johansson, my former cosupervisor, for your kind and helpful support. I really missed you when you left the group.

Thanks to all co-authors who contributed to the papers included in this thesis.

Aaro Haapaniemi, co-author and friend. You brought a fresh breeze to the lab with all your energy, positivity and ideas. Sometimes it was hard to keep up with all this energy $;$, but it was always a great pleasure and fun working with you and doing a part of this $\mathrm{PhD}$ - journey together.

Tatiana Jaklovska, Elina Mäki-Torkko and Petri Olivius, current and former heads of the ENT-department, for making it possible for me to pursue research.

All colleagues and friends at the ENT-department.

Café sällskapet and Café Linds for all the liters of Latte during the writing of this thesis. My amazing family, my parents Johann and Herta Tiefenböck for unlimited support and love. Thank you for believing in me, for always being there for me and for always helping me to make my dreams come true. You are the best parents one can wish for and I love you both endlessly! My wonderful sisters, Stefanie and Barbara Tiefenböck. We three have always completed each other and have shared all the ups and downs in life. Thank you for all the laughter and tears we shared. You are my very best friends and I have learned so much from you! I love you deeply and I am so lucky to have you! 
My precious Fredrik, my amazing husband. You are my whole life and the most wonderful person there is and I can't describe how grateful I am and how lucky I feel to have you in my life. Without you, your love and endless support, this thesis would not have been possible. You really are the wind beneath my wings and I love you more than anything in this world. "You and me, ALWAYS and FOREVER"...

\section{Funding}

This research was made possible with funds from The Swedish Cancer Society, the Swedish Laryng Foundation, the Foundation of Åke Wiberg, the County Council of Östergötland, the Research Funds of Linköping University Hospital, the Cancer Foundation of Östergötland, the Swedish Research Council and the Foundation of Acta Oto-Laryngologica. 



\section{REFERENCES}

1. Cancer Fact sheet: World Health Organisation; 2017 [updated February 20172017 August 8]. Available from: http://www.who.int/mediacentre/factsheets/fs297/en/.

2. Sudhakar A. History of Cancer, Ancient and Modern Treatment Methods. J Cancer Sci Ther. 2009;1(2):1-4.

3. Mukherjee S. The Emperor of All Maladies: A Biography of Cancer. : Scribner, Division of Simon\&Schuster, Inc, New York; 2010.

4. Cancer: Wikipedia; 2017 [2017 August 30]. Available from: https://en.wikipedia.org/wiki/Cancer.

5. Farnebo L. Predictive markers: for treatment sensitivity in head and neck squamous cell carcinoma. Linköping: Linköping University Electronic Press: Linköping University; 2010.

6. Ferlay J, Soerjomataram I, Dikshit R, Eser S, Mathers C, Rebelo M, et al. Cancer incidence and mortality worldwide: sources, methods and major patterns in GLOBOCAN 2012. Int J Cancer. 2015;136(5):E359-86.

7. Amarasinghe NWJHK. Epidemiology and Aetiology of Head and Neck Cancers. In: Bernier J, editor. Head and Neck Cancer. Second ed: Springer International Publishing Switzerland 2016; 2016. p. 1-58.

8. Blot WJ, McLaughlin JK, Winn DM, Austin DF, Greenberg RS, Preston-Martin $\mathrm{S}$, et al. Smoking and drinking in relation to oral and pharyngeal cancer. Cancer Res. 1988;48(11):3282-7.

9. Hashibe M, Brennan P, Benhamou S, Castellsague X, Chen C, Curado MP, et al. Alcohol drinking in never users of tobacco, cigarette smoking in never drinkers, and the risk of head and neck cancer: pooled analysis in the International Head and Neck Cancer Epidemiology Consortium. J Natl Cancer Inst. 2007;99(10):777-89.

10. Bravi F, Bosetti C, Filomeno M, Levi F, Garavello W, Galimberti S, et al. Foods, nutrients and the risk of oral and pharyngeal cancer. Br J Cancer. 2013;109(11):290410.

11. Hashim D, Sartori S, Brennan P, Curado MP, Wunsch-Filho V, Divaris K, et al. The role of oral hygiene in head and neck cancer: results from International Head and Neck Cancer Epidemiology (INHANCE) consortium. Ann Oncol. 2016;27(8):1619-25.

12. Maier H, Zoller J, Herrmann A, Kreiss M, Heller WD. Dental status and oral hygiene in patients with head and neck cancer. Otolaryngol Head Neck Surg. 1993;108(6):655-61.

13. D'Souza G, Kreimer AR, Viscidi R, Pawlita M, Fakhry C, Koch WM, et al. Case-control study of human papillomavirus and oropharyngeal cancer. N Engl J Med. 2007;356(19):1944-56. 


\section{REFERENCES}

14. Strome SE, Savva A, Brissett AE, Gostout BS, Lewis J, Clayton AC, et al. Squamous cell carcinoma of the tonsils: a molecular analysis of HPV associations. Clin Cancer Res. 2002;8(4):1093-100.

15. Young LS, Dawson CW. Epstein-Barr virus and nasopharyngeal carcinoma. Chin J Cancer. 2014;33(12):581-90.

16. Gupta B, Johnson NW. Emerging and established global life-style risk factors for cancer of the upper aero-digestive tract. Asian Pac J Cancer Prev. 2014;15(15):5983-91.

17. Marur S, Forastiere AA. Head and Neck Squamous Cell Carcinoma: Update on Epidemiology, Diagnosis, and Treatment. Mayo Clin Proc. 2016;91(3):386-96.

18. Llewellyn CD, Johnson NW, Warnakulasuriya KA. Risk factors for squamous cell carcinoma of the oral cavity in young people--a comprehensive literature review. Oral Oncol. 2001;37(5):401-18.

19. Spence T, Bruce J, Yip KW, Liu FF. HPV Associated Head and Neck Cancer. Cancers (Basel). 2016;8(8).

20. Baskar R, Lee KA, Yeo R, Yeoh KW. Cancer and radiation therapy: current advances and future directions. Int J Med Sci. 2012;9(3):193-9.

21. Eriksson D, Stigbrand T. Radiation-induced cell death mechanisms. Tumour Biol. 2010;31(4):363-72.

22. Parsons JT, Greene BD. Summary of major radiation fractionation and chemotherapy trials for organ preservation therapy in locally advanced head and neck squamous cell carcinoma. Pract Radiat Oncol. 2015;5(5):343-9.

23. Zackrisson B, Kjellen E, Soderstrom K, Brun E, Nyman J, Friesland S, et al. Mature results from a Swedish comparison study of conventional versus accelerated radiotherapy in head and neck squamous cell carcinoma - The ARTSCAN trial. Radiother Oncol. 2015;117(1):99-105.

24. Marta GN, Silva V, de Andrade Carvalho H, de Arruda FF, Hanna SA, Gadia R, et al. Intensity-modulated radiation therapy for head and neck cancer: systematic review and meta-analysis. Radiother Oncol. 2014;110(1):9-15.

25. Blanchard P, Baujat B, Holostenco V, Bourredjem A, Baey C, Bourhis J, et al. Meta-analysis of chemotherapy in head and neck cancer (MACH-NC): a comprehensive analysis by tumour site. Radiother Oncol. 2011;100(1):33-40.

26. Pignon JP, le Maitre A, Maillard E, Bourhis J, Group M-NC. Meta-analysis of chemotherapy in head and neck cancer (MACH-NC): an update on 93 randomised trials and 17,346 patients. Radiother Oncol. 2009;92(1):4-14.

27. Cmelak AJ, Arneson K, Chau NG, Gilbert RW, Haddad RI. Locally advanced head and neck cancer. Am Soc Clin Oncol Educ Book. 2013:237-44.

28. Specenier P, Vermorken JB. Cetuximab: its unique place in head and neck cancer treatment. Biologics. 2013;7:77-90. 
29.

Huang SM, Bock JM, Harari PM. Epidermal growth factor receptor blockade with C225 modulates proliferation, apoptosis, and radiosensitivity in squamous cell carcinomas of the head and neck. Cancer Res. 1999;59(8):1935-40.

30. Bonner JA, Harari PM, Giralt J, Cohen RB, Jones CU, Sur RK, et al. Radiotherapy plus cetuximab for locoregionally advanced head and neck cancer: 5-year survival data from a phase 3 randomised trial, and relation between cetuximab-induced rash and survival. Lancet Oncol. 2010;11(1):21-8.

31. Ang KK, Zhang Q, Rosenthal DI, Nguyen-Tan PF, Sherman EJ, Weber RS, et al. Randomized phase III trial of concurrent accelerated radiation plus cisplatin with or without cetuximab for stage III to IV head and neck carcinoma: RTOG 0522. J Clin Oncol. 2014;32(27):2940-50.

32. Riaz N, Sherman E, Koutcher L, Shapiro L, Katabi N, Zhang Z, et al. Concurrent Chemoradiotherapy With Cisplatin Versus Cetuximab for Squamous Cell Carcinoma of the Head and Neck. Am J Clin Oncol. 2016;39(1):27-31.

33. Johnson FM, Saigal B, Talpaz M, Donato NJ. Dasatinib (BMS-354825) tyrosine kinase inhibitor suppresses invasion and induces cell cycle arrest and apoptosis of head and neck squamous cell carcinoma and non-small cell lung cancer cells. Clin Cancer Res. 2005;11(19 Pt 1):6924-32.

34. Brooks HD, Glisson BS, Bekele BN, Johnson FM, Ginsberg LE, El-Naggar A, et al. Phase 2 study of dasatinib in the treatment of head and neck squamous cell carcinoma. Cancer. 2011;117(10):2112-9.

35. Lin YC, Wu MH, Wei TT, Chuang SH, Chen KF, Cheng AL, et al. Degradation of epidermal growth factor receptor mediates dasatinib-induced apoptosis in head and neck squamous cell carcinoma cells. Neoplasia. 2012;14(6):463-75.

36. Wilson C, Nicholes K, Bustos D, Lin E, Song Q, Stephan JP, et al. Overcoming EMT-associated resistance to anti-cancer drugs via Src/FAK pathway inhibition. Oncotarget. 2014;5(17):7328-41.

37. Nantajit D, Lin D, Li JJ. The network of epithelial-mesenchymal transition: potential new targets for tumor resistance. J Cancer Res Clin Oncol. 2015;141(10):1697-713.

38. Keith B, Simon MC. Hypoxia-inducible factors, stem cells, and cancer. Cell. 2007; 129(3):465-72.

39. Heddleston JM, Li Z, Lathia JD, Bao S, Hjelmeland AB, Rich JN. Hypoxia inducible factors in cancer stem cells. Br J Cancer. 2010;102(5):789-95.

40. Mani SA, Guo W, Liao MJ, Eaton EN, Ayyanan A, Zhou AY, et al. The epithelial-mesenchymal transition generates cells with properties of stem cells. Cell. 2008;133(4):704-15.

41. Vaupel P, Harrison L. Tumor hypoxia: causative factors, compensatory mechanisms, and cellular response. Oncologist. 2004;9 Suppl 5:4-9. 


\section{REFERENCES}

42. Swartz JE, Pothen AJ, Stegeman I, Willems SM, Grolman W. Clinical implications of hypoxia biomarker expression in head and neck squamous cell carcinoma: a systematic review. Cancer Med. 2015;4(7):1101-16.

43. Sasabe E, Zhou X, Li D, Oku N, Yamamoto T, Osaki T. The involvement of hypoxia-inducible factor-1alpha in the susceptibility to gamma-rays and chemotherapeutic drugs of oral squamous cell carcinoma cells. Int J Cancer. 2007;120(2):268-77.

44. Kalluri R, Weinberg RA. The basics of epithelial-mesenchymal transition. J Clin Invest. 2009;119(6):1420-8.

45. Hay ED. An overview of epithelio-mesenchymal transformation. Acta Anat (Basel). 1995;154(1):8-20.

46. Hanahan D, Weinberg RA. The hallmarks of cancer. Cell. 2000;100(1):57-70.

47. Kao SH, Wu KJ, Lee WH. Hypoxia, Epithelial-Mesenchymal Transition, and TET-Mediated Epigenetic Changes. J Clin Med. 2016;5(2).

48. Skvortsova I, Skvortsov S, Raju U, Stasyk T, Riesterer O, Schottdorf EM, et al. Epithelial-to-mesenchymal transition and c-myc expression are the determinants of cetuximab-induced enhancement of squamous cell carcinoma radioresponse. Radiother Oncol. 2010;96(1):108-15.

49. La Fleur L, Johansson AC, Roberg K. A CD44high/EGFRlow subpopulation within head and neck cancer cell lines shows an epithelial-mesenchymal transition phenotype and resistance to treatment. PLoS One. 2012;7(9):e44071.

50. Jerhammar F, Ceder R, Garvin S, Grenman R, Grafstrom RC, Roberg K. Fibronectin 1 is a potential biomarker for radioresistance in head and neck squamous cell carcinoma. Cancer Biol Ther. 2010;10(12):1244-51.

51. Jouppila-Matto A, Narkio-Makela M, Soini Y, Pukkila M, Sironen R, Tuhkanen $\mathrm{H}$, et al. Twist and snail expression in pharyngeal squamous cell carcinoma stroma is related to cancer progression. BMC Cancer. 2011;11:350.

52. Tang Y, Liang X, Zheng M, Zhu Z, Zhu G, Yang J, et al. Expression of c-kit and Slug correlates with invasion and metastasis of salivary adenoid cystic carcinoma. Oral Oncol. 2010;46(4):311-6.

53. Hazan RB, Phillips GR, Qiao RF, Norton L, Aaronson SA. Exogenous expression of $\mathrm{N}$-cadherin in breast cancer cells induces cell migration, invasion, and metastasis. J Cell Biol. 2000;148(4):779-90.

54. Nijkamp MM, Span PN, Hoogsteen IJ, van der Kogel AJ, Kaanders JH, Bussink J. Expression of E-cadherin and vimentin correlates with metastasis formation in head and neck squamous cell carcinoma patients. Radiother Oncol. 2011;99(3):344-8.

55. Satelli A, Li S. Vimentin in cancer and its potential as a molecular target for cancer therapy. Cell Mol Life Sci. 2011;68(18):3033-46. 
56.

Reya T, Morrison SJ, Clarke MF, Weissman IL. Stem cells, cancer, and cancer stem cells. Nature. 2001;414(6859):105-11.

57. Prince ME, Sivanandan R, Kaczorowski A, Wolf GT, Kaplan MJ, Dalerba P, et al. Identification of a subpopulation of cells with cancer stem cell properties in head and neck squamous cell carcinoma. Proc Natl Acad Sci U S A. 2007;104(3):973-8.

58. Pozzi V, Sartini D, Rocchetti R, Santarelli A, Rubini C, Morganti S, et al. Identification and characterization of cancer stem cells from head and neck squamous cell carcinoma cell lines. Cell Physiol Biochem. 2015;36(2):784-98.

59. Ballman KV. Biomarker: Predictive or Prognostic? J Clin Oncol. 2015;33(33):3968-71.

60. Hanahan D, Weinberg RA. Hallmarks of cancer: the next generation. Cell. 2011;144(5):646-74.

61. Mahotka C, Liebmann J, Wenzel M, Suschek CV, Schmitt M, Gabbert HE, et al. Differential subcellular localization of functionally divergent survivin splice variants. Cell Death Differ. 2002;9(12):1334-42.

62. Cheung CH, Huang CC, Tsai FY, Lee JY, Cheng SM, Chang YC, et al. Survivin - biology and potential as a therapeutic target in oncology. Onco Targets Ther. 2013;6:145362.

63. Marioni G, D'Alessandro E, Bertolin A, Staffieri A. Survivin multifaceted activity in head and neck carcinoma: current evidence and future therapeutic challenges. Acta Otolaryngol. 2010;130(1):4-9.

64. Lo Muzio L, Farina A, Rubini C, Pezzetti F, Stabellini G, Laino G, et al. Survivin as prognostic factor in squamous cell carcinoma of the oral cavity. Cancer Lett. 2005;225(1):27-33.

65. Preuss SF, Weinell A, Molitor M, Semrau R, Stenner M, Drebber U, et al. Survivin and epidermal growth factor receptor expression in surgically treated oropharyngeal squamous cell carcinoma. Head Neck. 2008;30(10):1318-24.

66. Dong Y, Sui L, Watanabe Y, Sugimoto K, Tokuda M. Survivin expression in laryngeal squamous cell carcinomas and its prognostic implications. Anticancer Res. 2002;22(4):2377-83.

67. Freier K, Pungs S, Sticht C, Flechtenmacher C, Lichter P, Joos S, et al. High survivin expression is associated with favorable outcome in advanced primary oral squamous cell carcinoma after radiation therapy. Int J Cancer. 2007;120(4):942-6.

68. Engels K, Knauer SK, Metzler D, Simf C, Struschka O, Bier C, et al. Dynamic intracellular survivin in oral squamous cell carcinoma: underlying molecular mechanism and potential as an early prognostic marker. J Pathol. 2007;211(5):532-40.

69. Garg H, Suri P, Gupta JC, Talwar GP, Dubey S. Survivin: a unique target for tumor therapy. Cancer Cell Int. 2016;16:49. 


\section{REFERENCES}

70. Coumar MS, Tsai FY, Kanwar JR, Sarvagalla S, Cheung CH. Treat cancers by targeting survivin: just a dream or future reality? Cancer Treat Rev. 2013;39(7):802-11.

71. Stauber RH, Mann W, Knauer SK. Nuclear and cytoplasmic survivin: molecular mechanism, prognostic, and therapeutic potential. Cancer Res. 2007;67(13):5999-6002.

72. Lippert BM, Knauer SK, Fetz V, Mann W, Stauber RH. Dynamic survivin in head and neck cancer: molecular mechanism and therapeutic potential. Int J Cancer. 2007;121(6):1169-74.

73. Mahmoudi S, Henriksson S, Weibrecht I, Smith S, Soderberg O, Stromblad S, et al. WRAP53 is essential for Cajal body formation and for targeting the survival of motor neuron complex to Cajal bodies. PLoS Biol. 2010;8(11):e1000521.

74. Zhong F, Savage SA, Shkreli M, Giri N, Jessop L, Myers T, et al. Disruption of telomerase trafficking by TCAB1 mutation causes dyskeratosis congenita. Genes Dev. 2011;25(1):11-6.

75. Mahmoudi S, Henriksson S, Farnebo L, Roberg K, Farnebo M. WRAP53 promotes cancer cell survival and is a potential target for cancer therapy. Cell Death Dis. 2011;2:e114.

76. Zhang H, Wang DW, Adell G, Sun XF. WRAP53 is an independent prognostic factor in rectal cancer- a study of Swedish clinical trial of preoperative radiotherapy in rectal cancer patients. BMC Cancer. 2012;12:294.

77. Mahmoudi S, Henriksson S, Corcoran M, Mendez-Vidal C, Wiman KG, Farnebo M. Wrap53, a natural p53 antisense transcript required for p53 induction upon DNA damage. Mol Cell. 2009;33(4):462-71.

78. Henriksson S, Farnebo M. On the road with WRAP53beta: guardian of Cajal bodies and genome integrity. Front Genet. 2015;6:91.

79. Venteicher AS, Abreu EB, Meng Z, McCann KE, Terns RM, Veenstra TD, et al. A human telomerase holoenzyme protein required for Cajal body localization and telomere synthesis. Science. 2009;323(5914):644-8.

80. Henriksson S, Rassoolzadeh H, Hedstrom E, Coucoravas C, Julner A, Goldstein $\mathrm{M}$, et al. The scaffold protein WRAP53beta orchestrates the ubiquitin response critical for DNA double-strand break repair. Genes Dev. 2014;28(24):2726-38.

81. Silwal-Pandit L, Russnes H, Borgen E, Skarpeteig V, Moen Vollan HK, Schlichting E, et al. The Sub-Cellular Localization of WRAP53 Has Prognostic Impact in Breast Cancer. PLoS One. 2015;10(10):e0139965.

82. Mahajan A. Practical issues in the application of p16 immunohistochemistry in diagnostic pathology. Hum Pathol. 2016;51:64-74.

83. Wells A. EGF receptor. Int J Biochem Cell Biol. 1999;31(6):637-43.

84. Argiris A, Karamouzis MV, Raben D, Ferris RL. Head and neck cancer. Lancet. 2008;371(9625):1695-709. 
85.

Ang KK, Berkey BA, Tu X, Zhang HZ, Katz R, Hammond EH, et al. Impact of epidermal growth factor receptor expression on survival and pattern of relapse in patients with advanced head and neck carcinoma. Cancer Res. 2002;62(24):7350-6.

86. Downward J, Parker P, Waterfield MD. Autophosphorylation sites on the epidermal growth factor receptor. Nature. 1984;311(5985):483-5.

87. Nyati MK. Box 2/ The main downstream signallin pathways regulated by EGFR Nature Reviews Cancer: Nature; 2006 [Available from: http://www.nature.com/nrc/journal/v6/n11/box/nrc1953 BX2.html.

88. Li X, Lu Y, Liang K, Pan T, Mendelsohn J, Fan Z. Requirement of hypoxiainducible factor-1alpha down-regulation in mediating the antitumor activity of the antiepidermal growth factor receptor monoclonal antibody cetuximab. Mol Cancer Ther. 2008;7(5):1207-17.

89. Zhong H, De Marzo AM, Laughner E, Lim M, Hilton DA, Zagzag D, et al. Overexpression of hypoxia-inducible factor 1alpha in common human cancers and their metastases. Cancer Res. 1999;59(22):5830-5.

90. Vogelstein B, Lane D, Levine AJ. Surfing the p53 network. Nature. 2000;408(6810):307-10.

91. Vousden KH, Lu X. Live or let die: the cell's response to p53. Nat Rev Cancer. 2002;2(8):594-604.

92. Poeta ML, Manola J, Goldwasser MA, Forastiere A, Benoit N, Califano JA, et al. TP53 mutations and survival in squamous-cell carcinoma of the head and neck. N Engl J Med. 2007;357(25):2552-61.

93.

Brookes AJ. The essence of SNPs. Gene. 1999;234(2):177-86.

94. Schildkraut JM, Goode EL, Clyde MA, Iversen ES, Moorman PG, Berchuck A, et al. Single nucleotide polymorphisms in the TP53 region and susceptibility to invasive epithelial ovarian cancer. Cancer Res. 2009;69(6):2349-57.

95. Garcia-Closas M, Kristensen V, Langerod A, Qi Y, Yeager M, Burdett L, et al. Common genetic variation in TP53 and its flanking genes, WDR79 and ATP1B2, and susceptibility to breast cancer. Int J Cancer. 2007;121(11):2532-8.

96. Borchiellini D, Etienne-Grimaldi MC, Thariat J, Milano G. The impact of pharmacogenetics on radiation therapy outcome in cancer patients. A focus on DNA damage response genes. Cancer Treat Rev. 2012;38(6):737-59.

97. Zhu Y, Yang H, Chen Q, Lin J, Grossman HB, Dinney CP, et al. Modulation of DNA damage/DNA repair capacity by XPC polymorphisms. DNA Repair (Amst). 2008;7(2):141-8.

98. Alsbeih G, El-Sebaie M, Al-Harbi N, Al-Buhairi M, Al-Hadyan K, Al-Rajhi N. Radiosensitivity of human fibroblasts is associated with amino acid substitution variants in susceptible genes and correlates with the number of risk alleles. Int J Radiat Oncol Biol Phys. 2007;68(1):229-35. 


\section{REFERENCES}

99. Bange J, Prechtl D, Cheburkin Y, Specht K, Harbeck N, Schmitt M, et al. Cancer progression and tumor cell motility are associated with the FGFR4 $\operatorname{Arg}(388)$ allele. Cancer Res. 2002;62(3):840-7.

100. Streit S, Bange J, Fichtner A, Ihrler S, Issing W, Ullrich A. Involvement of the FGFR4 Arg388 allele in head and neck squamous cell carcinoma. Int J Cancer. 2004;111(2):213-7.

101. da Costa Andrade VC, Parise O, Jr., Hors CP, de Melo Martins PC, Silva AP, Garicochea B. The fibroblast growth factor receptor 4 (FGFR4) Arg388 allele correlates with survival in head and neck squamous cell carcinoma. Exp Mol Pathol. 2007;82(1):53-7.

102. Bond GL, Hu W, Levine A. A single nucleotide polymorphism in the MDM2 gene: from a molecular and cellular explanation to clinical effect. Cancer Res. 2005;65(13):5481-4.

103. Tu HF, Chen HW, Kao SY, Lin SC, Liu CJ, Chang KW. MDM2 SNP 309 and p53 codon 72 polymorphisms are associated with the outcome of oral carcinoma patients receiving postoperative irradiation. Radiother Oncol. 2008;87(2):243-52.

104. Birner P, Oberhuber G, Stani J, Reithofer C, Samonigg H, Hausmaninger H, et al. Evaluation of the United States Food and Drug Administration-approved scoring and test system of HER-2 protein expression in breast cancer. Clin Cancer Res. 2001;7(6):1669-75.

105. Kim SW, Roh J, Park CS. Immunohistochemistry for Pathologists: Protocols, Pitfalls, and Tips. J Pathol Transl Med. 2016;50(6):411-8.

106. Haapaniemi A, Koivunen P, Saarilahti K, Kinnunen I, Laranne J, Aaltonen LM, et al. Laryngeal cancer in Finland: A 5-year follow-up study of 366 patients. Head Neck. 2016;38(1):36-43.

107. Preuss SF, Weinell A, Molitor M, Stenner M, Semrau R, Drebber U, et al. Nuclear survivin expression is associated with HPV-independent carcinogenesis and is an indicator of poor prognosis in oropharyngeal cancer. Br J Cancer. 2008;98(3):627-32.

108. Chen XQ, Yang S, Li ZY, Lu HS, Kang MQ, Lin TY. Effects and mechanism of downregulation of survivin expression by RNA interference on proliferation and apoptosis of lung cancer cells. Mol Med Rep. 2012;5(4):917-22.

109. Wang Y, Zhu H, Quan L, Zhou C, Bai J, Zhang G, et al. Downregulation of survivin by RNAi inhibits the growth of esophageal carcinoma cells. Cancer Biol Ther. 2005;4(9):974-8.

110. Kennedy SM, O'Driscoll L, Purcell R, Fitz-Simons N, McDermott EW, Hill AD, et al. Prognostic importance of survivin in breast cancer. Br J Cancer. 2003;88(7):107783.

111. Ponnelle T, Chapusot C, Martin L, Bouvier AM, Plenchette S, Faivre J, et al. Cellular localisation of survivin: impact on the prognosis in colorectal cancer. J Cancer Res Clin Oncol. 2005;131(8):504-10. 
112. Marioni G, Ottaviano G, Lionello M, Fasanaro E, Staffieri C, Giacomelli L, et al. A panel of biomarkers for predicting response to postoperative RT for laryngeal cancer? Am J Otolaryngol. 2014;35(6):771-8.

113. Nix P, Cawkwell L, Patmore H, Greenman J, Stafford N. Bcl-2 expression predicts radiotherapy failure in laryngeal cancer. Br J Cancer. 2005;92(12):2185-9.

114. Fairlie J, Harrington L. Enforced telomere elongation increases the sensitivity of human tumour cells to ionizing radiation. DNA Repair (Amst). 2015;25:54-9.

115. McCaul JA, Gordon KE, Minty F, Fleming J, Parkinson EK. Telomere dysfunction is related to the intrinsic radio-resistance of human oral cancer cells. Oral Oncol. 2008;44(3):261-9.

116. Hedstrom E, Pederiva C, Farnebo J, Nodin B, Jirstrom K, Brennan DJ, et al. Downregulation of the cancer susceptibility protein WRAP53beta in epithelial ovarian cancer leads to defective DNA repair and poor clinical outcome. Cell Death Dis. 2015;6:e1892.

117. Lydiatt WM, Patel SG, O'Sullivan B, Brandwein MS, Ridge JA, Migliacci JC, et al. Head and Neck cancers-major changes in the American Joint Committee on cancer eighth edition cancer staging manual. CA Cancer J Clin. 2017;67(2):122-37.

118. Wittekindt C, Gultekin E, Weissenborn SJ, Dienes HP, Pfister HJ, Klussmann JP. Expression of p16 protein is associated with human papillomavirus status in tonsillar carcinomas and has implications on survival. Adv Otorhinolaryngol. 2005;62:72-80.

119. Combes JD, Franceschi S. Role of human papillomavirus in non-oropharyngeal head and neck cancers. Oral Oncol. 2014;50(5):370-9.

120. Stephen JK, Divine G, Chen KM, Chitale D, Havard S, Worsham MJ. Significance of p16 in Site-specific HPV Positive and HPV Negative Head and Neck Squamous Cell Carcinoma. Cancer Clin Oncol. 2013;2(1):51-61.

121. Kalfert D, Celakovsky P, Laco J, Ludvikova M. The role of protein p16(INK4a) in glottic laryngeal squamous cell carcinoma. Pathol Oncol Res. 2014;20(4):909-15.

122. Baumann JL, Cohen S, Evjen AN, Law JH, Vadivelu S, Attia A, et al. Human papillomavirus in early laryngeal carcinoma. Laryngoscope. 2009;119(8):1531-7.

123. Chen C, Wei Y, Hummel M, Hoffmann TK, Gross M, Kaufmann AM, et al. Evidence for epithelial-mesenchymal transition in cancer stem cells of head and neck squamous cell carcinoma. PLoS One. 2011;6(1):e16466.

124. Jayachandran A, Dhungel B, Steel JC. Epithelial-to-mesenchymal plasticity of cancer stem cells: therapeutic targets in hepatocellular carcinoma. J Hematol Oncol. 2016;9(1):74.

125. Chinn SB, Darr OA, Peters RD, Prince ME. The role of head and neck squamous cell carcinoma cancer stem cells in tumorigenesis, metastasis, and treatment failure. Front Endocrinol (Lausanne). 2012;3:90. 


\section{REFERENCES}

126. Carnero A, Lleonart M. The hypoxic microenvironment: A determinant of cancer stem cell evolution. Bioessays. 2016;38 Suppl 1:S65-74.

127. Boeckx C, Van den Bossche J, De Pauw I, Peeters M, Lardon F, Baay M, et al. The hypoxic tumor microenvironment and drug resistance against EGFR inhibitors: preclinical study in cetuximab-sensitive head and neck squamous cell carcinoma cell lines. BMC Res Notes. 2015;8:203.

128. Jedlinski A, Garvin S, Johansson AC, Edqvist PH, Ponten F, Roberg K. Cetuximab sensitivity of head and neck squamous cell carcinoma xenografts is associated with treatment-induced reduction in EGFR, pEGFR, and pSrc. J Oral Pathol Med. 2016.

129. Zecchini V, Madhu B, Russell R, Pertega-Gomes N, Warren A, Gaude E, et al. Nuclear ARRB1 induces pseudohypoxia and cellular metabolism reprogramming in prostate cancer. EMBO J. 2014;33(12):1365-82.

130. Luwor RB, Lu Y, Li X, Mendelsohn J, Fan Z. The antiepidermal growth factor receptor monoclonal antibody cetuximab/C225 reduces hypoxia-inducible factor-1 alpha, leading to transcriptional inhibition of vascular endothelial growth factor expression. Oncogene. 2005;24(27):4433-41.

131. Holz C, Niehr F, Boyko M, Hristozova T, Distel L, Budach V, et al. Epithelialmesenchymal-transition induced by EGFR activation interferes with cell migration and response to irradiation and cetuximab in head and neck cancer cells. Radiother Oncol. 2011;101(1):158-64.

132. Stalhammar G, Fuentes Martinez N, Lippert M, Tobin NP, Molholm I, Kis L, et al. Digital image analysis outperforms manual biomarker assessment in breast cancer. Mod Pathol. 2016;29(4):318-29. 


\section{Papers}

The papers associated with this thesis have been removed for copyright reasons. For more details about these see:

http:// urn.kb.se/ resolve?urn=urn:nbn:se:liu:diva-142112 